\title{
The Effect of Street Orientation on Outdoor Thermal Comfort in a Cold Mountainous Climate
}

\author{
Narges Delpak ${ }^{1}$, Hassan Sajadzadeh ${ }^{1, *}$, Saide Hasanpourfard ${ }^{2}$ and Farshid Aram ${ }^{3}$ \\ 1 Department of Urban Design, Bu-Ali Sina University, Hamedan 94171-71946, Iran; \\ edu.delpak.n07@gmail.com \\ 2 Institute of Higher Education ACECR of Hamadan, Hamadan, Iran; hassanpoor2003@gmail.com \\ 3 Escuela Técnica Superior de Arquitectura, Universidad Politécnica de Madrid-UPM, Madrid 28040, Spain; \\ Farshid.aram@alumnos.upm.es \\ * Correspondence: sajadzadeh@basu.ac.ir,
}

\begin{abstract}
Lack of due attention to the orientation of streets and establishment of urban blocks without regard for climatic characteristics and conditions of the environment have an adverse effect on thermal comfort in open urban spaces. Construction of new settlements without taking into account climatic requirements undermines thermal comfort for pedestrians and other users, especially in cold regions. Considering the coldness of the region under study and the significance of the orientation of streets in absorbing radiation and providing heat to outdoor urban spaces, this study investigates the effect of the orientation of streets on microclimatic comfort in one of the residential towns of Hamadan City in Iran. For this purpose, microclimate simulation was performed using ENVI-met software. A residential block with four different orientations (the most common orientations of its surrounding buildings) were simulated in the coldest day of winter and the hottest day of summer. The results suggest that streets have different thermal behavior in different orientations. Orientation affects mean radiant temperature (Tmrt), the duration of exposure to direct sunlight, wind speed, and physiological equivalent temperature (PET), which are all important factors in thermal comfort. Based on these findings, north-south streets in Hamedan receive more radiant temperature during winter compared to other simulated orientations and provide more desirable thermal comfort. The average PET value on a winter day at a point on the north-south passage was 4.5-8 ${ }^{\circ} \mathrm{C}$ warmer than other orientations. In summer, streets with intercardinal orientations (i.e., northeast-southwest and northwest-southeast) provided the lowest PET (about $2{ }^{\circ} \mathrm{C}$ cooler than other orientations) and better thermal comfort
\end{abstract}

Keywords: Thermal Comfort; Outdoor Space; Microclimate Simulation; Street Orientation; Physiological Equivalent Temperature

\section{Introduction}

About 50 percent of the world's population live in cities and this figure is expected to rise to 80 percent in 2030 [1]. Under the influence of urban density, lack of vegetation, increasing heat from human activities and pollution, these urban microclimates have begun to crawl toward warmer temperatures and lower air quality [2]. The outdoor urban thermal conditions became a significant area of interest for researchers who were trying to devise new strategies in sustainable urban planning [3]. As such, most recent studies have been conducted by researchers in the fields of architecture, geography, climatology and biometrics. The subject of thermal comfort in outdoor urban space was not given much attention up until the early 21st century [4]. The outdoor thermal comfort (OTC) is one of the most important factors that directly affects the perceived quality of outdoor urban spaces [5] and public participation in outdoor activities. Therefore, OTC has attracted considerably more attention in recent years [6]. Well-designed outdoor spaces and 
thermally-comfortable environments can improve public health and well-being [7], tourism, open space usage and social interactions [9,8]. There is a close relationship between buildings and their external environments [10]. Each building changes the climatic conditions around it to some extent. The geometry, shape, height and size of buildings, the direction of streets and buildings and the area of open spaces all affect urban microclimates [11]. The orientation of buildings and neighborhood units relative to one another, the distribution of buildings at a given site and building density affect indoor energy consumption, access to sunlight, wind flow and climatic conditions in each region [12].

During the last century, numerous studies have attempted to assess thermal conditions, to define thermal comfort for humans and to categorize heat stress levels [13]. Recently, inclination toward carrying out studies about OTC has increased [14]. Comfort refers to a sense of satisfaction resulting from a balance between an individual's physiological, psychological and physical aspects and their environment [5,7]. Comfort has various subtypes ranging from thermal, acoustic, visual, and aesthetics [15].

Thermal indicators are divided into empirical group (effective temperature (ET), resultant temperature (RT), humid operative temperature (HOP), operative temperature (OP) and wind chill index (WCI)) and the analytical group (index of thermal stress (ITS), heat stress index (HIS), standard effective temperature (SET), outdoor standard effective temperature (OUTSET), predicted mean vote (PMV), perceived temperature (PT) and PET) (Fanger, 1972; Givoni, 1976; Ashrae, 2001). The most common method for examining climatic comfort is PMV which has been proposed by Fanger as an empirical measure of sense of thermal comfort [12]. Later on, this measure became a basis for the standards of indoor thermal comfort such as ISO 7730-1984 and ASHRAE 55-1992 [12]. Studies that have analyzed the validity of this indicator in outdoor space report that the rate of thermal sensation is less than predicted mean vote (PMV) [16] and the reason might be cultural, social, psychological and behavioral factors. PET is based on the model of human thermal balance and is composed of air parameters and other thermal and physiological factors like clothing and activity type.

PET helps researchers compare the collective effect of outdoor thermal conditions with one's personal experience [17]. Although PET has been defined in terms of virtual indoor conditions, it can also be applied to real-world outdoor conditions. This indicator is included in urban and regional planning guidelines in Germany, where it is used to predict thermal changes in urban or regional climates [18]. Studies which have tried to validate this indicator have found it to be strongly associated with the feeling of thermal comfort in various outdoor conditions [19]. Tmrt is an influential factor related to PET [20]. This index is used to measure a person's thermal comfort under specific conditions as compared to their physiological responses to thermal conditions in a reference environment. PET can be described as a temperature in which human body can achieve thermal balance while sitting in an indoor space without any wind or sunlight [21]. It is a comprehensive and highly useful indicator for evaluating biological conditions and identifying potential tourist climates [22]. The difference between PMV and PET is that PET makes use of actual skin temperature as well as evaporation and perspiration levels whereas PMV is a function of the average skin temperature and internal body temperature [23]. Based on this indicator the range of $18-23^{\circ} \mathrm{C}$ is thermally comfortable for humans [Table1]. Six variables that affect OTC are radiation, wind, humidity, environmental temperature, physical activity and clothing [24] .

\subsection{The Effect of Street Orientation on Thermal Comfort}

In many recent studies, the orientation of streets and blocks has been mentioned as one of the most important design factors that affect OTC [14]. Taleghani et al. [12], for example, have simulated some of the east-west and north-south streets in Netherlands on the hottest day of the year using ENVI-met software. The results showed that Tmrt plays the most important role in thermal comfort. Other studies have shown that north-south streets provide the highest level of outdoor comfort for pedestrians while the east-west orientation can be the worst [25] [26]. East-west streets experience intense sunlight and 
have the highest Tmrt [25]. Some studies have found out that northeast-southwest is the best orientation for streets in urban planning [27] [28]. Street orientation has also a significant impact on air flow at the pedestrian level [28]. Streets in the same direction of prevailing winds experience the highest rate of wind speed, which can may intensify by low height/width ratio [29] [25]. A research carried out in 2012 on streets with different widths $(10,15,20$ and 25 meters) in the east-west and north-south orientations reported that eastwest streets do not receive radiation during winter but receive direct radiation during the mornings and afternoons of summer days. The research also reported that north-south passages, even the narrowest of them, receive limited radiation for a short time on the shortest day of the year but are strongly exposed to radiation in the morning and evening [30]. A study carried out in Brazil examined the impact of the orientation of streets (relative to the prevailing wind) on wind speed and spatial turbulence and reported the notable effect on human thermal comfort [31]. Another study about urban open spaces in the geographical coordinates of 34-26 degrees north using Shading software states that northsouth rectangular yards (larger side positioned east-west) provide the best orientation for cooling and that the north-south orientation provides access to direct sunlight at the center of the yard in a very short time [32]. Overall, street orientation has a significant effect on PET in relation to wind speed and direction [33].

\subsection{The Effect of Sky View Factor on Thermal Comfort}

Many studies have addressed the effect of sky view factor (SVF) on urban-climatic variables. SVF is defined as the proportion of the radiation received by a flat surface from the total radiation received by the hemisphere which covers the surface [34] . In SVF rating, zero means total absence of view toward the sky while 1 means a complete view of the sky. Bouria and Awbi investigated the effect of enclosure and sky view in a building complex on outdoor microclimate in El-Oued, Algeria, and concluded that controlling SVF and street architecture can prevent temperature rise in urban canyons, which has a stronger effect on the local, rather than citywide, scale [35]. Bourbia and Boucheriba have examined surface temperature and outdoor temperature in seven sites with varying height/width ratios ranging from 1 to 4.8 and different SVF values ranging from 0.076 to 0.58 in Constantine, Algeria. They discovered that higher height/width ratios decrease both air temperature and surface temperature. In hot climates, a higher SVF results in a higher outdoor temperature [36] . Research findings in Taiwan have demonstrated that high values of SVF can lead to thermal discomfort during summer while low values may lead to discomfort during winter [37] [17]. There is no global standard for the threshold of SVF. The optimum range of SVF in an area should be determined based on the studies conducted in that specific area. In the majority of studies, surface temperature has been associated with SVF and this confirms the existence of a relationship between these two parameters.

As the urban population of Hamedan grew, new neighborhoods emerged in the city. The majority of the city's recent developments in both public and private sectors have utilized varying methods without being regulated by specified standards. The variety of the residential sites in a suburban developing area of the city in terms of morphology (i.e., form, orientation, and density) attracted the attention of the authors. The morphological differences of this area compared to the older residential districts of the city can be indicated through a number of research and renovation projects. While some studies have explored thermal comfort in Chamran Street in Kermanshah City (e.g. Jafari, Taban and Saffaripour, 2020) [38], lack of sufficient research in the cold and mountainous climate of the region on the one hand and the importance of provision of thermal comfort in new residential complexes on the other hand highlight the significance of this study. The authors have focused on street orientation as a major criterion of morphology. Field assessments as well as quantitative (software) and qualitative analysis were performed on a newly 
built building complex with emphasis on street orientation. Shortage of studies about design morphology in the literature of architecture and urban design in the cold and mountainous climate encouraged the authors to conduct this research in a city with this specific kind of climate with the aim of assessing one of the indicators of design morphology, namely street orientation. This study evaluates the effect of street orientation on OTC via microclimatic simulation of a residential block in ENVI-met software in north-south, northwest-southeast, east-west, and northeast-southwest orientations with the aim of measuring the indicators that affect thermal comfort such as air temperature, relative humidity, wind speed, Tmrt, and PET. Considering the fact that not much in-depth research has been done about the orientations of urban open spaces in the residential blocks located in the cold and mountainous climate of Iran and given that inappropriate orientations in residential blocks can have many negative effects on thermal comfort and energy consumption, this study seeks to determine the best orientation for streets and open public spaces via analysis of the orientations from the perspective of climatic comfort to provide a suitable model for urban planning and development in these areas. This model can then be used to achieve urban sustainability. To this end, certain fundamental questions had to be answered: What is the best way to achieve thermal comfort in the cold and mountainous climate? What is the relationship between the SVF and thermal comfort in different orientations?

\section{Research Method}

As described in the first section, the aim of this study was to analyze the effect of street orientation on thermal comfort in the outdoor space of a residential block in the cold and mountainous climate. Four orientations were studied in the residential block via microclimatic simulation in ENVI-met software. Since simulating an entire year was extremely difficult, this study is limited to two sample days, one in summer and one in winter. These days were selected from among the coldest and warmest days of the year based on the average temperature data in order to provide a general representation of the region's extreme climatic conditions. In the first step, information about the site in question was collected using detailed urban plans, aerial photos and field observations. For 3D simulation, accurate data about the type of building materials including the flooring of the streets and soil parameters were entered into the software.

The meteorological data required for the simulation including wind speed and direction, minimum and maximum temperature as well as minimum and maximum relative humidity were retrieved from Hamedan Meteorological Station. This information along with certain geographical parameters such as longitude, latitude, and altitude were used in the simulation of the microclimate. After the simulation, the output parameters such as temperature, Tmrt, humidity, wind speed, SVF, and PET were recorded as numerical data and graphs. Figure 1 shows the framework of the research. 


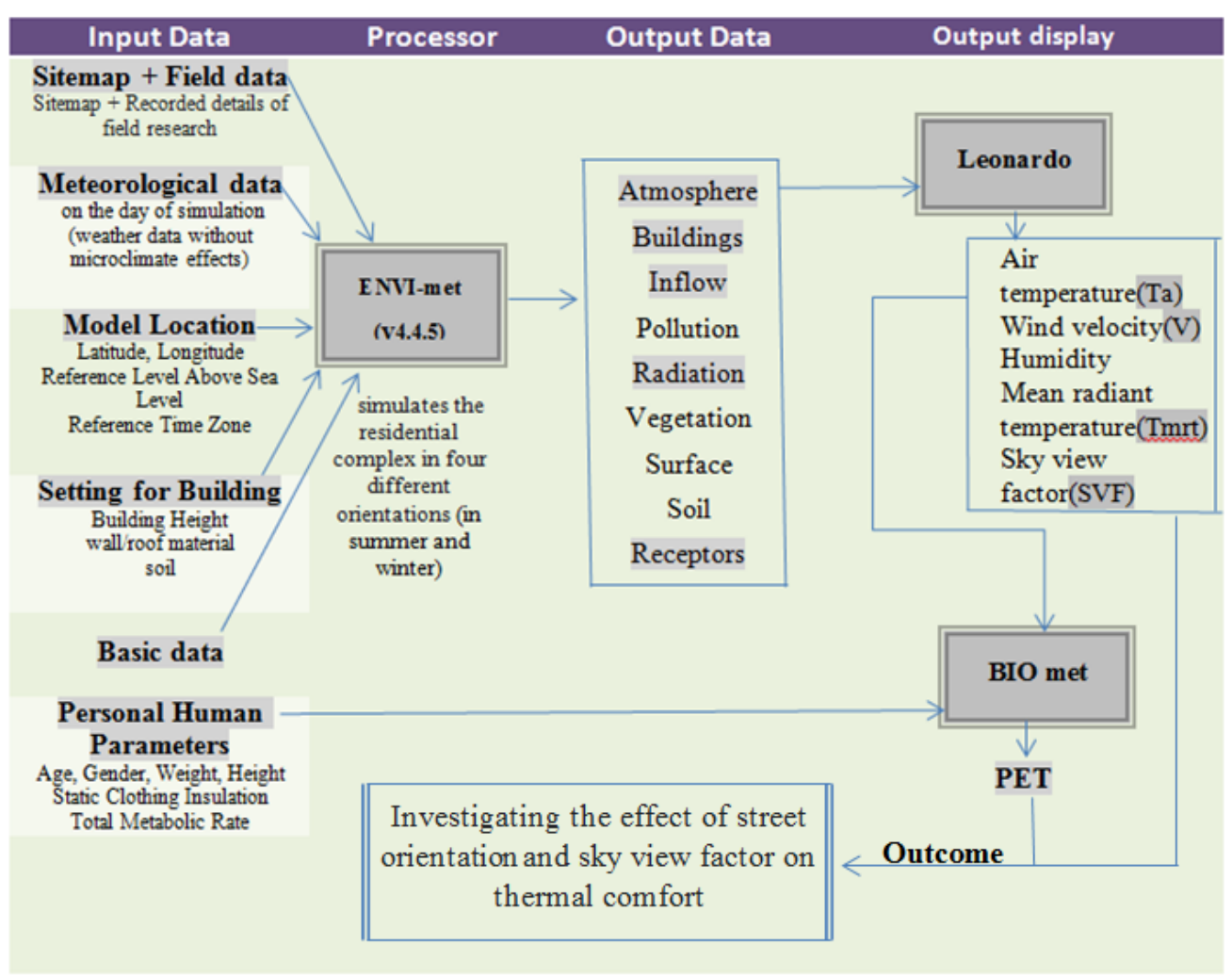

Figure 1. Research Framework

\subsection{Physiological Equivalent Temperature (PET) Index}

Physiological equivalent temperature (PET) has been explored and used in many studies [39] [40] [41] [42]. PET has been found out to be an effective criterion for measuring OTC in almost all climatic conditions. Obtained based on Tmrt, wet-bulb globe temperature (WBGT), wind speed and air temperature, PET can be used to assess OTC [43]. Apart from meteorological parameters, behavioral factors such as clothing and metabolic rate are included in PET calculations in Biomet software. In this study, PET was used to determine the hours in the 06:00-18:00 temporal range which provide thermal comfort on a summer day and a winter day. Table 1 shows the standard values for thermal sensation/stress levels associated with each PET range.

Table 1- PET values for different levels of human thermal perception [44]

\begin{tabular}{|c|c|c|}
\hline PET ${ }^{\circ} \mathbf{C}$ & Thermal Perception & Grade of physiological stress \\
\hline 4 & Very cold & Extreme cold stress \\
\hline & Cold & Strong cold stress \\
\hline 8 & Cool & Moderate cold stress \\
\hline 13 & Slightly cool & Slight cold stress \\
\hline 18 & Comfortable & No thermal stress \\
\hline
\end{tabular}




\begin{tabular}{ccc}
\hline 23 & & \\
29 & Slightly warm & Slight heat stress \\
& Warm & Moderate heat stress \\
\hline 41 & Hot & Strong heat stress \\
\cline { 1 - 2 } & Very hot & Extreme heat stress
\end{tabular}

\subsection{Simulation Software}

ENVI-met v4.4.5 which was designed by the German researcher Michael Bruse is used for microclimate simulation of urban environments. It is the only software package that can integrate all parameters of thermal comfort such as wind speed and direction, mean radiant temperature, air temperature, etc. into the simulation [28]. The present researchers used this package to examine the effect of their design on the quality and comfort of the microclimate [12], [46], [47]. It helps to study urban microclimate through different perspectives such as architecture, landscape architecture, urban planning, and human thermal comfort. The simulation model is use for small scales with a horizontal resolution of 1 to 5 meters, a timespan of 24 to 48 hours, and time intervals of 1 to 5 seconds. This high resolution allows for the analysis of small-scale interactions between buildings, surfaces, and plants. Taleghani et al. studied the effectiveness of this software package. They compared field records with the software output and observed a correlation of 0.8 and only a difference of $0.5^{\circ} \mathrm{C}$, which confirms its high capability of being used as a research tool [13].

\subsection{Study Sample}

The site of the study was in Hamedan City, west of Iran (Figure 2). Hamedan lies at an altitude of 1820 meters and has a cold, mountainous, and windy climate. It is located at a longitude of $49^{\circ} \mathrm{E}$ and a latitude of $35^{\circ} \mathrm{N}$. The average difference between the minimum and maximum temperature of the city is $23^{\circ} \mathrm{C}$. August is the warmest month with the average of $23.6{ }^{\circ} \mathrm{C}$ and February is the coldest month with an average of $0.6{ }^{\circ} \mathrm{C}$. Hamedan's climate is mainly influenced by Mediterranean air masses which enter Iran from the west. The northwest streams from the Black Sea and Northern Europe also affect the city's' climate. In general, Hamedan's climate is extremely variable due to high mountains, rivers and altitude variations. The winters are cold with large amounts of precipitation and the summers are moderate [46].

The following points can be mentioned based on climatic studies carried out in Hamedan: (1) maximum exposure to radiation, (2) minimum heat dissipation, (3) avoidance of winter cold (most of the year), (4) resistance against long-term frost and (5) the need to protect buildings against cold wind (southwest). Therefore, heat exchange via the walls, roofs and vents should be minimized, heat loss should be prevented, sunlight should be fully used for heating, cold winds should be prevented from entering buildings in cold seasons, drafts should be utilized whenever necessary and shadows should be controlled [47]. One of the features of the cold mountain climate is the huge temperature difference between night and day and between winter and summer. Relatively low humidity, cold winds blowing from the west and from the direction of mountains and prolonged frost periods are among the other features of this climate. Compared to cold and humid regions, cold and mountainous areas are affected by climatic changes to a greater degree. In addition, rainfall changes in cold and wet areas are more common compared to cold and dry regions. Based on monthly changes, the highest temperature rise in cold and humid 
climates occurs in February and March while most tangible temperature changes in cold and mountainous areas occur during January and February [48].

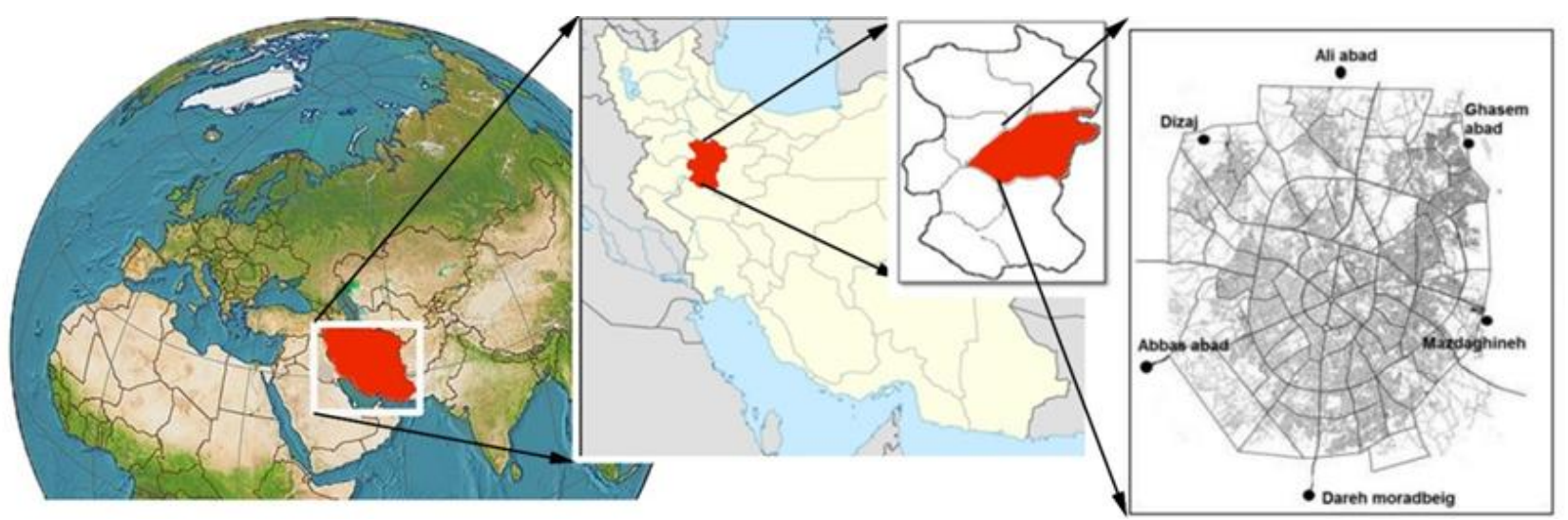

Figure 2.Geographical location of Iran and Hamadan city

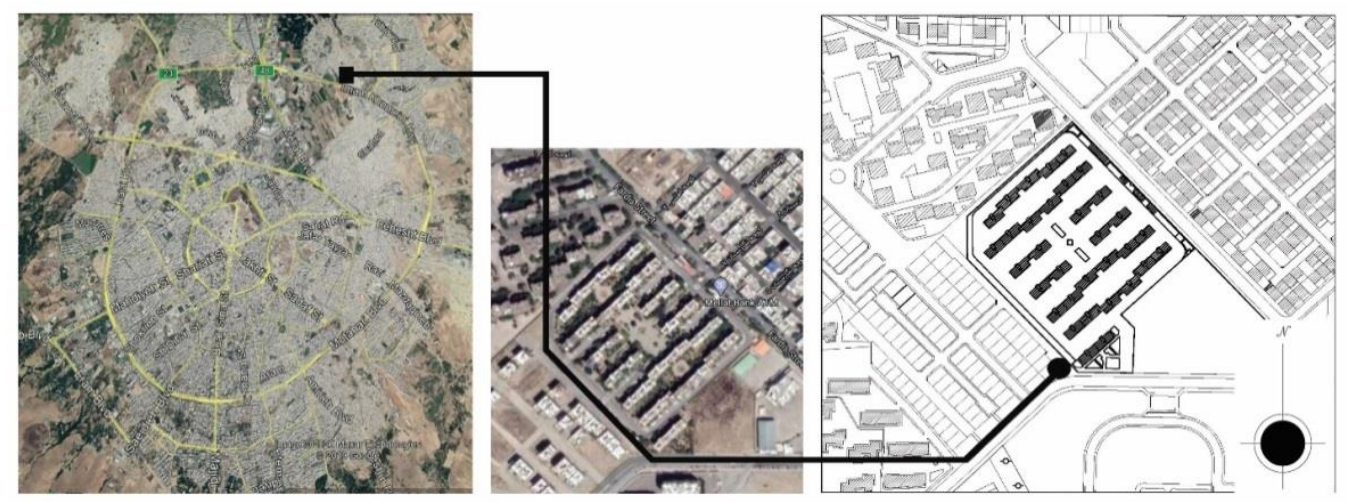

Figure 3. Location of the site of the block under study in Hamadan

\subsection{Microclimatic Simulation in the Residential Block under Study}

The simulation was performed for winter and summer in four orientations, i.e., northeast-southwest, east-west, northwest-southeast, and north-south. The current orientation of the block is northeast-southwest (Figure 4). Software simulation was conducted in two scenarios for winter and summer without vegetation (in the outdoor spaces). The simulation of summertime is based on the data of August 5, 2019, as August is the warmest month of the year.
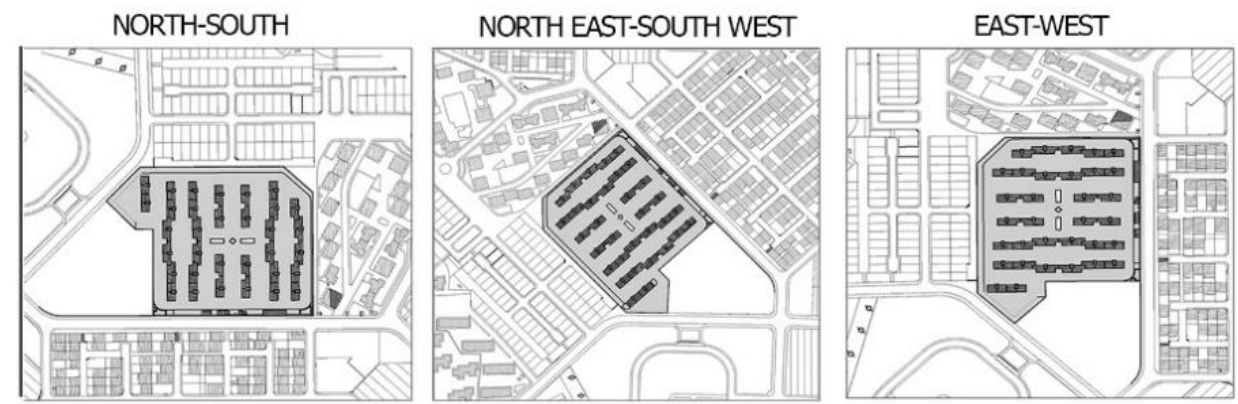

NORTH WEST-SOUTH EAST

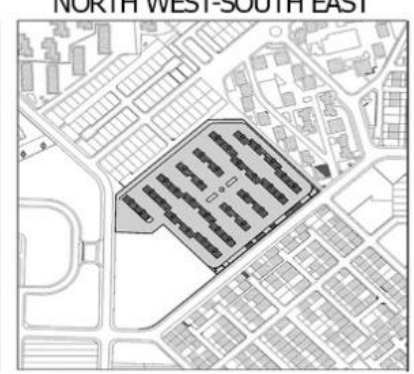

Figure 4- The simulated orientations in ENVI-met 
The simulation's duration was 12 hours from 06:00 to 18:00. The simulation of winter was based on the data of February 04, 2020 (the coldest month of the year). The block was simulated in ENVI-met 4.4 .5 in a $2 \times 2$ grid according to the geographical location, the materials of the ground and surfaces, green spaces, and building heights. The required meteorological information was obtained from the website of Iran's Meteorological Organization and is listed in Table 2 (for winter) and Table 3 (for summer). Table 4 shows the information about the simulated site. Table 5 describes the type of building materials used in the simulation. Table 6 shows the default parameters of the person whose thermal behavior was investigated in the outdoor space.

Table2. Meteorological Information on February 4,2020 (Winter)

\begin{tabular}{|c|c|c|c|c|c|}
\hline $\begin{array}{c}\text { MaximumRelative } \\
\text { Humidity (\%) }\end{array}$ & $\begin{array}{c}\text { Mini- } \\
\text { mumRela- } \\
\text { tive } \\
\text { Humidity } \\
(\%)\end{array}$ & $\begin{array}{l}\text { Maximum } \\
\text { Temperature( } \\
\left.{ }^{\circ} \mathrm{c}\right)\end{array}$ & $\begin{array}{c}\text { Minimum } \\
\text { Temperature }\left({ }^{\circ} \mathrm{C}\right)\end{array}$ & $\begin{array}{l}\text { WindDi- } \\
\text { rection } \\
\text { (Digree) }\end{array}$ & $\begin{array}{c}\text { Wind } \\
\text { Speed }(\mathrm{m} / \mathrm{s})\end{array}$ \\
\hline 89 & 48 & +12 & -3 & $\begin{array}{l}\text { West } \\
(270)\end{array}$ & $3 / 5$ \\
\hline
\end{tabular}

Table3. Meteorological Information on August 6,2019 (Summer)

\begin{tabular}{|c|c|c|c|c|c|}
\hline $\begin{array}{c}\text { Maxi- } \\
\text { mumRela- } \\
\text { tive } \\
\text { Humidity } \\
(\%)\end{array}$ & $\begin{array}{c}\text { MinimumRelative } \\
\text { Humidity (\%) }\end{array}$ & $\begin{array}{l}\text { Maxi- } \\
\text { mum } \\
\text { Tem- } \\
\text { pera- } \\
\text { ture }\left({ }^{\circ} \mathrm{C}\right)\end{array}$ & $\begin{array}{l}\text { Mini- } \\
\text { mum } \\
\text { Tem- } \\
\text { pera- } \\
\left.\text { ture ( }{ }^{\circ} \mathrm{C}\right)\end{array}$ & $\begin{array}{l}\text { WindDi- } \\
\text { rection } \\
\text { (Digree) }\end{array}$ & $\begin{array}{c}\text { Wind } \\
\text { Speed }(\mathrm{m} / \mathrm{s})\end{array}$ \\
\hline 38 & 16 & +36 & +18 & West (270) & $3 / 5$ \\
\hline
\end{tabular}

Table4. Model Location on Earth

\begin{tabular}{cccccc}
\hline $\begin{array}{c}\text { Name of Lo- } \\
\text { cation }\end{array}$ & $\begin{array}{c}\text { Latitude } \\
(\mathrm{deg},+\mathrm{N},-\mathrm{S})\end{array}$ & $\begin{array}{c}\text { Longtitude } \\
(\mathrm{deg},+\mathrm{E},-\mathrm{W})\end{array}$ & $\begin{array}{c}\text { Reference Level Above } \\
\text { Sea Level }(\mathrm{m})\end{array}$ & $\begin{array}{c}\text { Reference } \\
\text { Time Zone }\end{array}$ & $\begin{array}{c}\text { Reference } \\
\text { Longtitude }\end{array}$ \\
\hline $\begin{array}{c}\text { Hama- } \\
\text { dan,Iran }\end{array}$ & +35 & +49 & 1820 & UTC & $3: 30$ \\
\hline
\end{tabular}

Table5. Setting for Building

\begin{tabular}{|c|c|c|c|c|c|}
\hline $\begin{array}{l}\text { Building } \\
\text { Height }(\mathrm{m})\end{array}$ & Wall Material & Roof Material & $\begin{array}{l}\text { Nr of Nest- } \\
\text { ing Grid }\end{array}$ & Soil A & Soil B \\
\hline 12 & $\begin{array}{c}\text { Default Wall- Moder- } \\
\text { ate Insulation }\end{array}$ & $\begin{array}{c}\text { Default Roof Moder- } \\
\text { ate Insulation }\end{array}$ & 0 & Lomy Soil & Lomy Soil \\
\hline
\end{tabular}

Table6. Personal Human Parameters

\begin{tabular}{cccccc}
\hline Age $(\mathrm{y})$ & Gender & $\begin{array}{c}\text { Weight(k } \\
\mathrm{g})\end{array}$ & Height(m) & $\begin{array}{c}\text { Static Clothing Insula- } \\
\text { tion(clo) }\end{array}$ & $\begin{array}{c}\text { Total Metabolic } \\
\text { Rate }(\mathrm{w} / \mathrm{m} 2)\end{array}$ \\
\hline \multirow{2}{*}{35} & Male & 75 & 1.75 & $\begin{array}{c}0.9 \text { (for Winter) } \\
0.5 \text { (for Summer) }\end{array}$ & 86.21 \\
\hline
\end{tabular}

Figure 5 shows the points in the outdoor space selected for measuring thermal comfort. Point A was evaluated and compared in the four orientations during a 12-hour span 
in terms of Tmrt, air temperature, wind speed, and PET. Points B1-B10 and C1-C10 which lie along two different streets on the site have hypothetical receptors. The reason for analysis of thermal comfort in these streets is the change of their width. In so doing, the effects of SFV and orientation on thermal comfort along the streets were simultaneously studied.

For evaluation of thermal comfort at these points, the graphs of Tmrt, PET, wind speed, and SVF were compared. It should be noted that the height of all linear buildings in this complex was 12 meters. The street width was 14 meters at point A, 18 meters at point B (except for the small square) and 14 meters at point $C$. The width of the central opening was 22 meters.

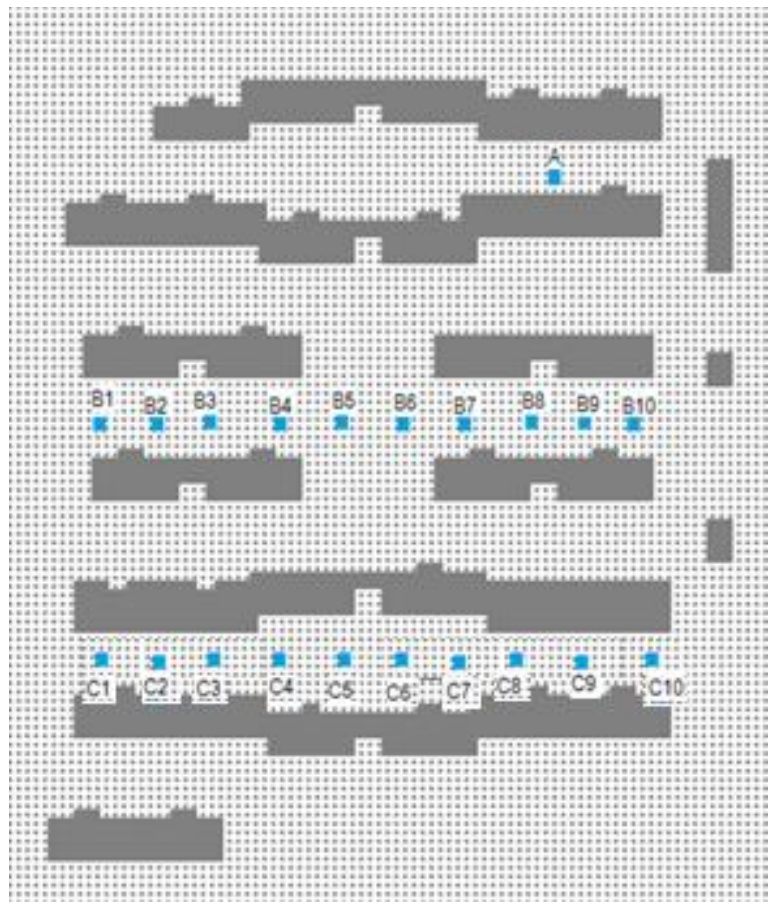

Figure 5. Location of the selected points between buildings

\section{Results and Discussion}

The orientation of streets and alleys is one of most influential design factors in OTC-based urban planning. Therefore, the microclimatic conditions and thermal comfort of the streets of the residential blocks in the selected site were simulated separately in four modes in winter (February) and summer (August). The following section discusses each mode.

\subsection{The Effect of Street Orientation on Thermal Comfort in the Microclimate}

To determine the best orientation in terms of OTC (Figure 3), simulation was conducted in the current orientation and three other orientations (Figure 4) in winter and summer. The site was simulated without any vegetation so that only the impact of orientation could be assessed 


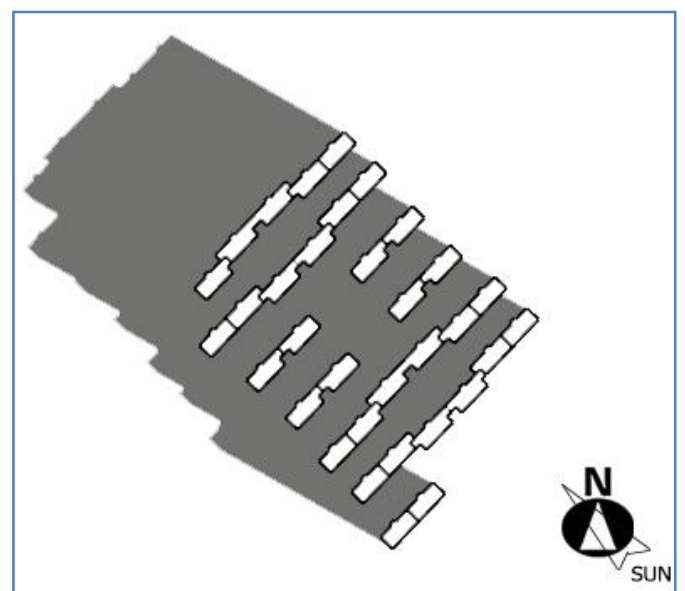

a) NE-SW orientation

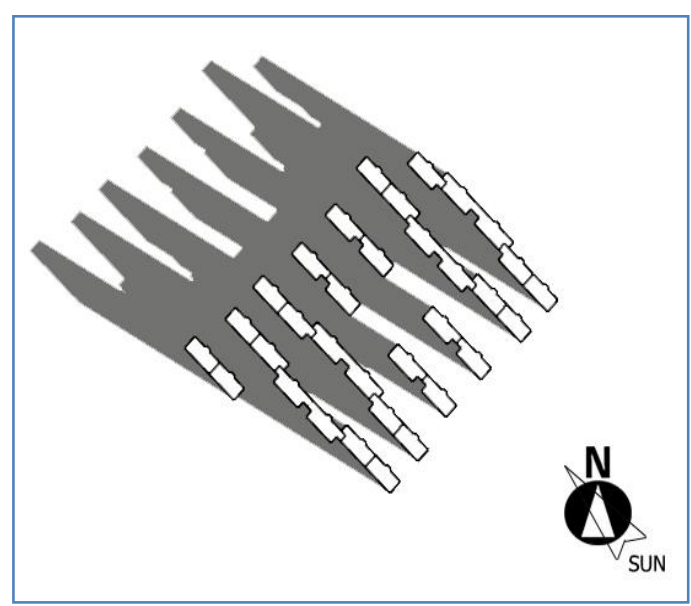

c) NW-SE Orientation

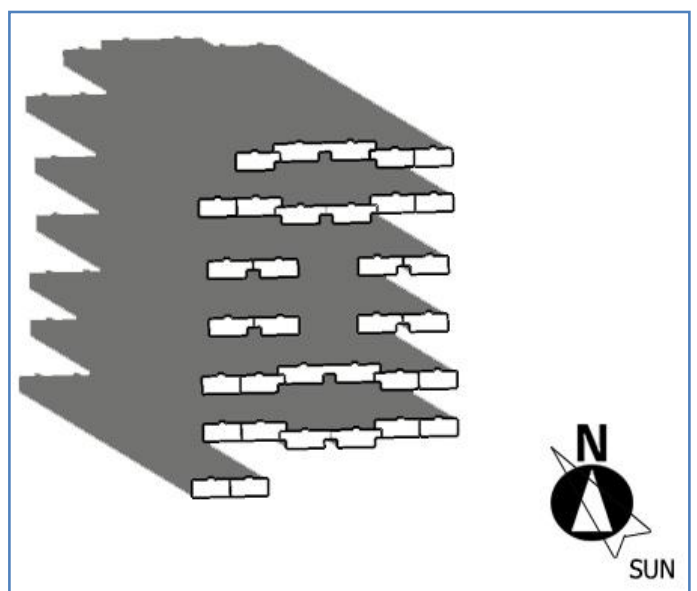

b) W-E orientation

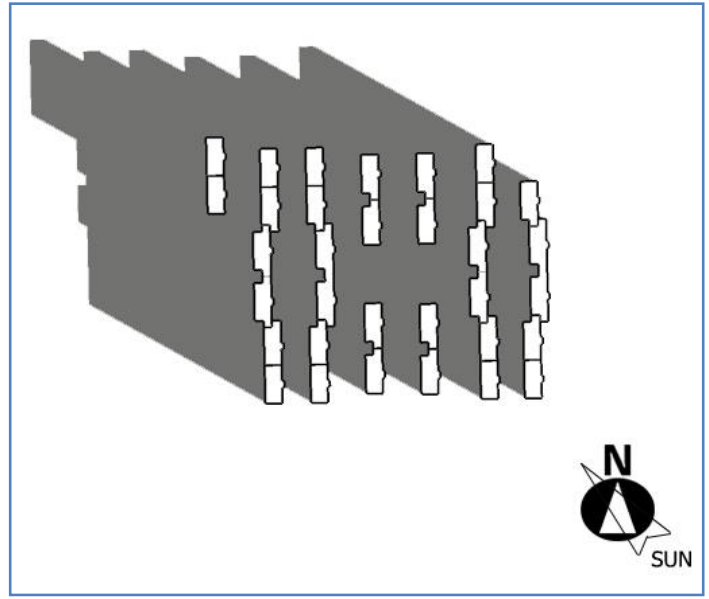

d) N-S Orientation

Figure 6. Different block orientations and their shading at 8:00 a.m. in the winter day

Figure 6 depicts Fardis Residential Complex in the simulated orientations along with the shading of the buildings at 06:00 on February 04. At this hour of a winter day, the sun shines from the southeast and sets on the southwest. The orientation of the streets relative to the position of the sun determines whether or not they receive radiation. As can be seen in the NE-SW orientation in Figure 6(a), the streets are in the shade until noon; thereafter, they receive full radiation until the sunset. The W-E orientation in Figure 6(b) shows that the streets receive less radiation and are in the shade for most of the day. The NW-SE orientation in Figure 6(c) shows that the streets receive radiation early in the day but fall in the shade for the rest of the day. The N-S orientation Figure 6(d) shows that the streets receive the highest amount of radiation in most hours of the day.

3.1.1. The Simulation Results in Four Different Orientations in Winter (February 4, 2020/ without Vegetation):

The microclimatic conditions of Point A in a winter dat (February 4, 2020)

Air temperature (Ta): The difference in air temperature between the different orientations is not significant. The highest recorded temperature, namely $11.7{ }^{\circ} \mathrm{C}$, belongs to the current orientation (NE-SW) at 12:00, which remains higher than the temperature of the other orientations until 15:00. The N-S orientation has the lowest recorded temperature with a difference of $1^{\circ} \mathrm{C}$ (Figure 7). 


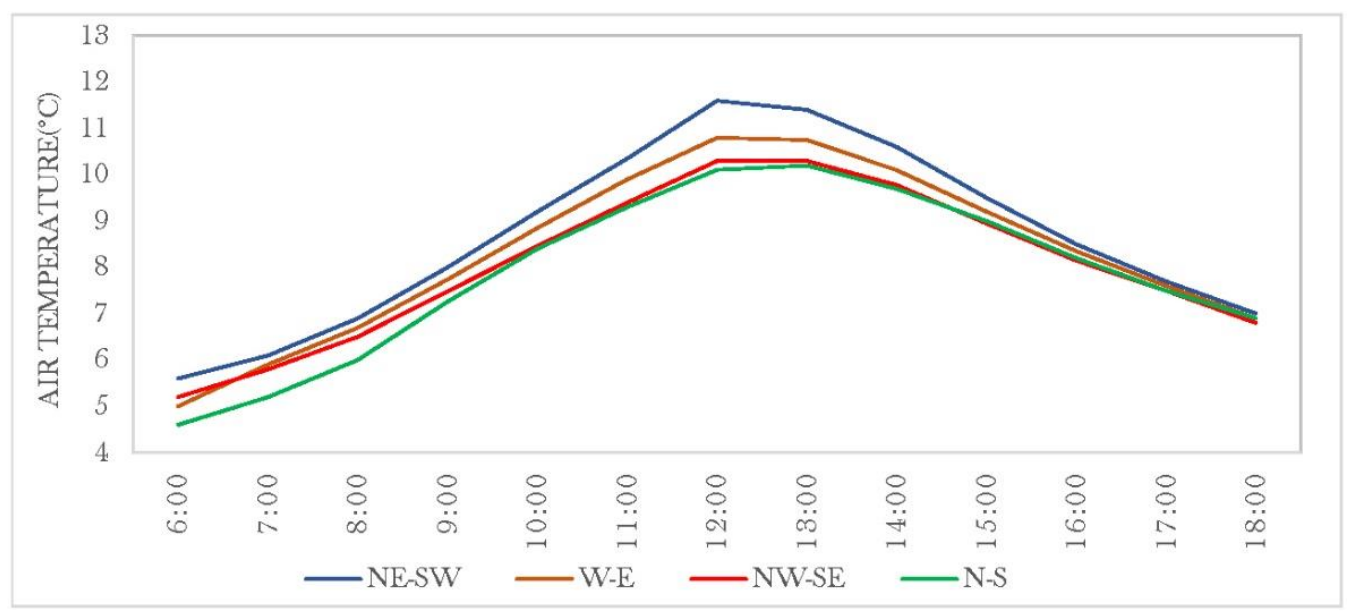

Figure 7- Comparison of air temperature values at Point A (in winter)

Wind speed: Based on the obtained meteorological information, the speed of the prevailing wind at the selected site is $3.5 \mathrm{~m} / \mathrm{s}$ which blows from the west. The wind's speed varies with its direction and the angle of the street unto which it blows. In the N-S orientation where the block's orientation is perpendicular to the wind direction, the wind speed is lowest $(0.3 \mathrm{~m} / \mathrm{s})$ but picks up a little during the evening hours. The highest wind speed $(1.8 \mathrm{~m} / \mathrm{s})$ belongs to the $\mathrm{W}-\mathrm{E}$ orientation which is the same as the wind direction (Figure 8 ). The wind speed in intercardinal orientations lies between these two values (1.3-1.5). As such, the rise in the wind speed in the E-W orientation reaches $1.5 \mathrm{~m} / \mathrm{s}$ relative to the N-S orientation.

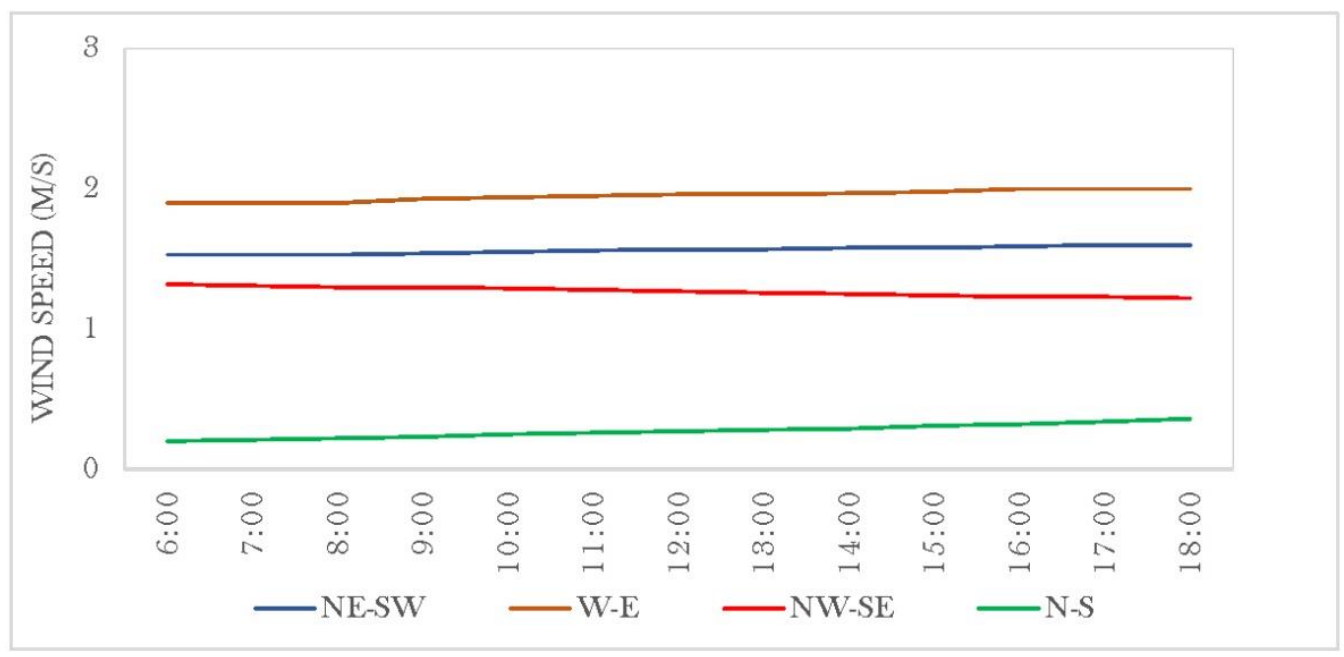

Figure 8: Wind speed comparison at Point A (in winter)

Mean radiant temperature (Tmrt): Analysis of Tmrt graph variations at Point A in different orientations in winter shows that in all orientations except for W-E, a leap in the radiant temperature can be observed in certain hours of the day (Figure 9). The maximum radiant temperature $\left(45-65^{\circ} \mathrm{C}\right)$ occurred at 06:00-08:00 in the NW-SE orientation, at 09:0010:00 in the N-S orientation and at 12:00-14:00 in the NW-SW orientation. These hours are the hours during which the streets received direct sunlight. In the E-W orientation, the maximum radiant temperature occurred at 10:00 and 12:00. The reason for the lower value of Tmrt in the E-W orientation compared to the other orientations is that it does not receive radiation during the day (Figure 6(b)). Therefore, Tmrt differences are substantial in the four orientations and even during different hours. 


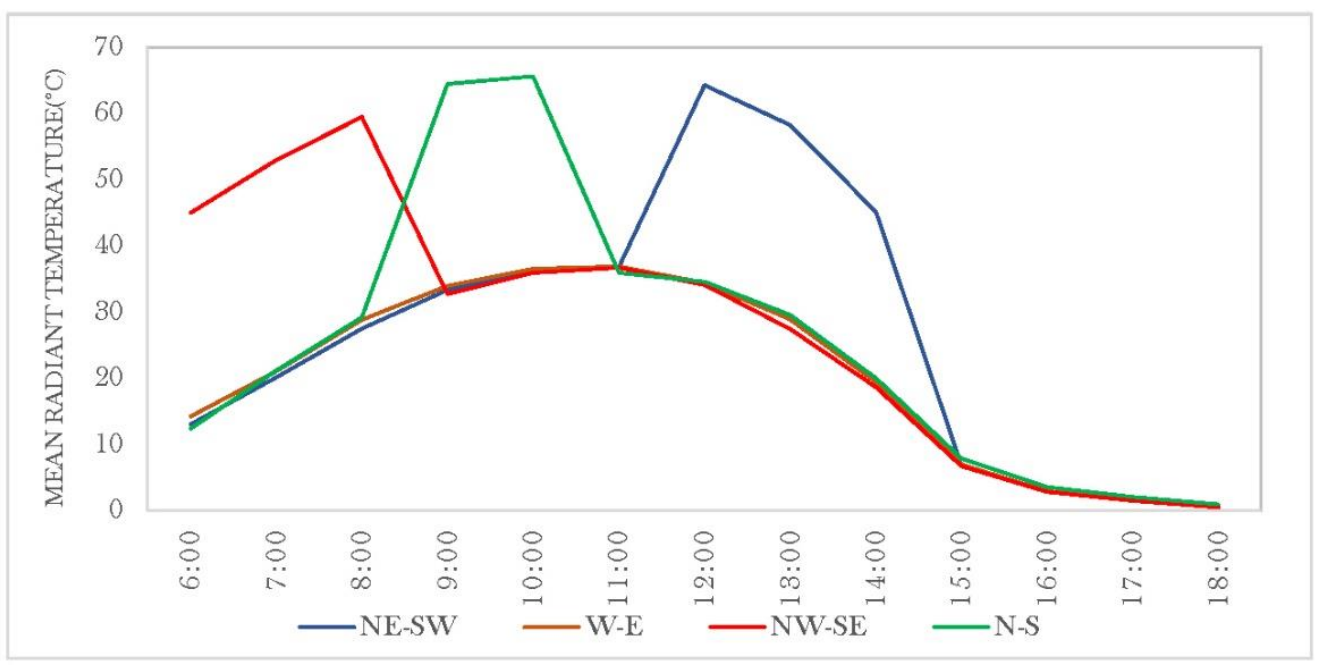

Figure 9: Mean radiant temperature comparison at Point A (in winter)

PET: Street orientation has a large impact on the value of PET in relation to wind speed and direction [49]. A comparison of the Tmrt and PET graphs indicates that in orientations and hours where the street has received the highest amount of radiation, PET has also increased (Figure 9 and Figure 10). In the N-S orientation, the maximum PET occured at 09:00-10:00 and the thermal comfort range was met at 11:00-12:00 (about $19{ }^{\circ} \mathrm{C}$ ). In the current orientation namely NE-SW, the thermal comfort range was met during 11:30-13:30. In the W-E orientation, the entire day was in a very cold temperature range because of lack of radiation and high wind speed. In the NW-SE orientation, the thermal comfort range was met only at 07:30-08:00 but the temperature decreased during the rest of the day.

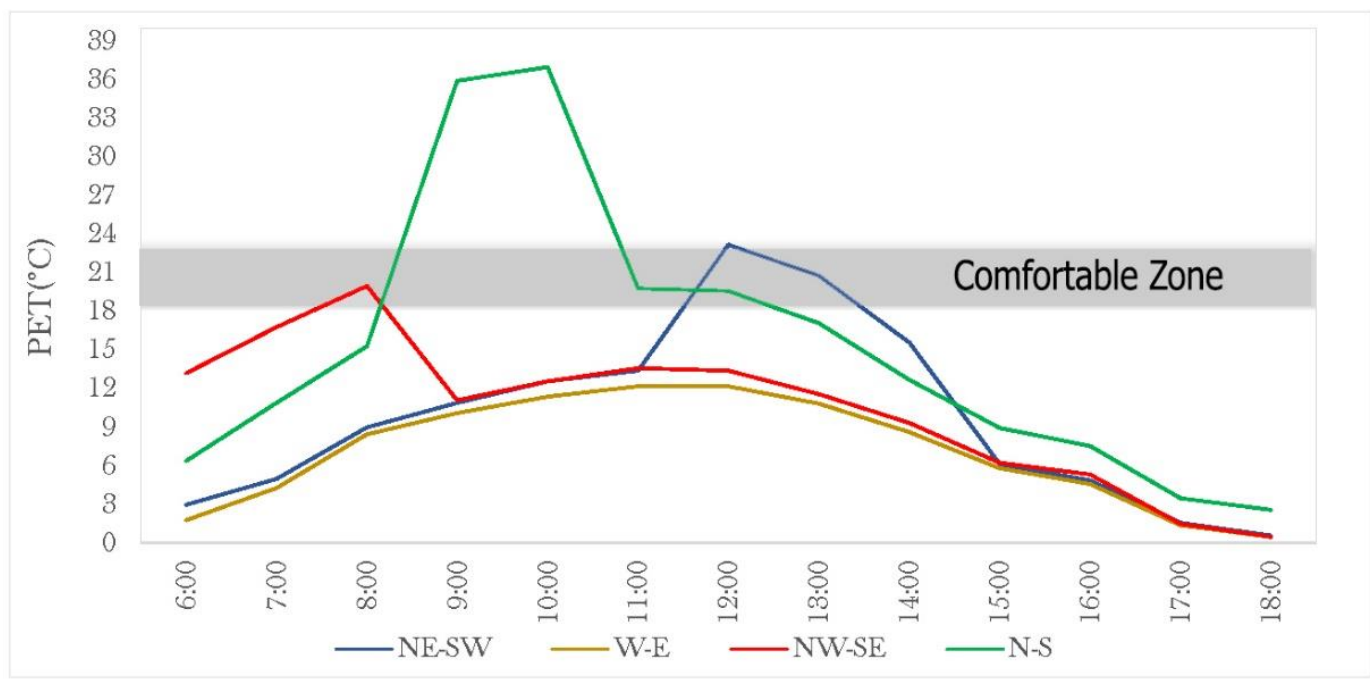

Figure 10: PET comparison at Point A (in winter)

Table 7 summarizes the mean values of microclimatic parameters for different orientations at point $\mathrm{A}$. The comparison of these values shows that mean PET is highest in the $\mathrm{N}-\mathrm{S}$ street and thus closest to the range of thermal comfort compared to other orientations. Street orientation has the strongest effect on radiant temperature and wind speed, which eventually results in different thermally comfortable hours in different orientations. The maximum value of Tmrt $\left(27.8^{\circ} \mathrm{C}\right)$ belongs to the NE-SW orientation and the minimum $(21$ $\left.{ }^{\circ} \mathrm{C}\right)$ to the $\mathrm{W}$-E orientation, which causes cold stress during many hours of the day during 
the cold seasons. This highlights the importance of Tmrt in the cold and mountainous climate. The highest Tmrt belongs to the most optimal orientation of the street. In addition, the speed of cold wind is lowest in the N-S orientation. The N-S orientation has the highest PET because it is optimally exposed to radiation and the wind speed is low. Also, the N$S$ orientation provides the longest thermal comfort period among all four orientations.

Table 7. Average Microclimate Quantities Comparison at Point A (in Winter)

\begin{tabular}{ccccccc}
\hline Orientation & $\mathrm{T}(\mathrm{c})$ & $\begin{array}{c}\text { Wind } \\
\text { speed(m/s) }\end{array}$ & $\begin{array}{c}\text { Spe- } \\
\text { cific } \\
\text { hu- } \\
\text { midity }\end{array}$ & Tmrt(c) & PET(c) & $\begin{array}{c}\text { Comfort- } \\
\text { able } \\
\text { Hours }\end{array}$ \\
\hline NE-SW & 8.9 & 1.7 & 3.7 & 27.8 & 9.7 & 2 \\
\hline N-S & 8.2 & 0.3 & 3.7 & 26.2 & 15.1 & 3 \\
\hline NW-SE & 8.3 & 1.3 & 3.7 & 25.8 & 10.4 & 1 \\
\hline W-E & 8.6 & 2 & 3.7 & 21 & 7.1 & 0
\end{tabular}

3.1.2. The microclimatic conditions in the paths $B$ and $C$ during the day in winter (February 4 , 2020):

The width of path $\mathrm{C}$ changes in some sections of Fardis Residential Complex. In addition, there is a disconnection (small square) along path B. Receptors were placed along these paths for examination of the effect of these changes on thermal comfort. The following section compares the changes which occurred in the thermal comfort (based on PET) of these paths for all orientations under study. Path B1-B10: Figure 11 shows the mean value of PET between 06:00 and 18:00 for all points on path B. In the N-S orientation, all points except B5 and B6 are in the comfort range. Wind speed increased at these two points since the geometry of the path changed and led to a sudden decrease in the PET value. This shows the notable effect of wind speed on thermal comfort during winter. The effect outweighs that of Tmrt.

After the N-S orientation, the NE-SW orientation has the most desirable PET value. The worst thermal comfort condition belongs to the W-E orientation, which has the highest rate of wind speed and receives the lowest amount of solar radiation throughout the day. The large difference in the values of PET in the different orientations $\left(6-24^{\circ} \mathrm{C}\right)$ shows the notable effect of orientation on thermal comfort during winter (Figure 10).

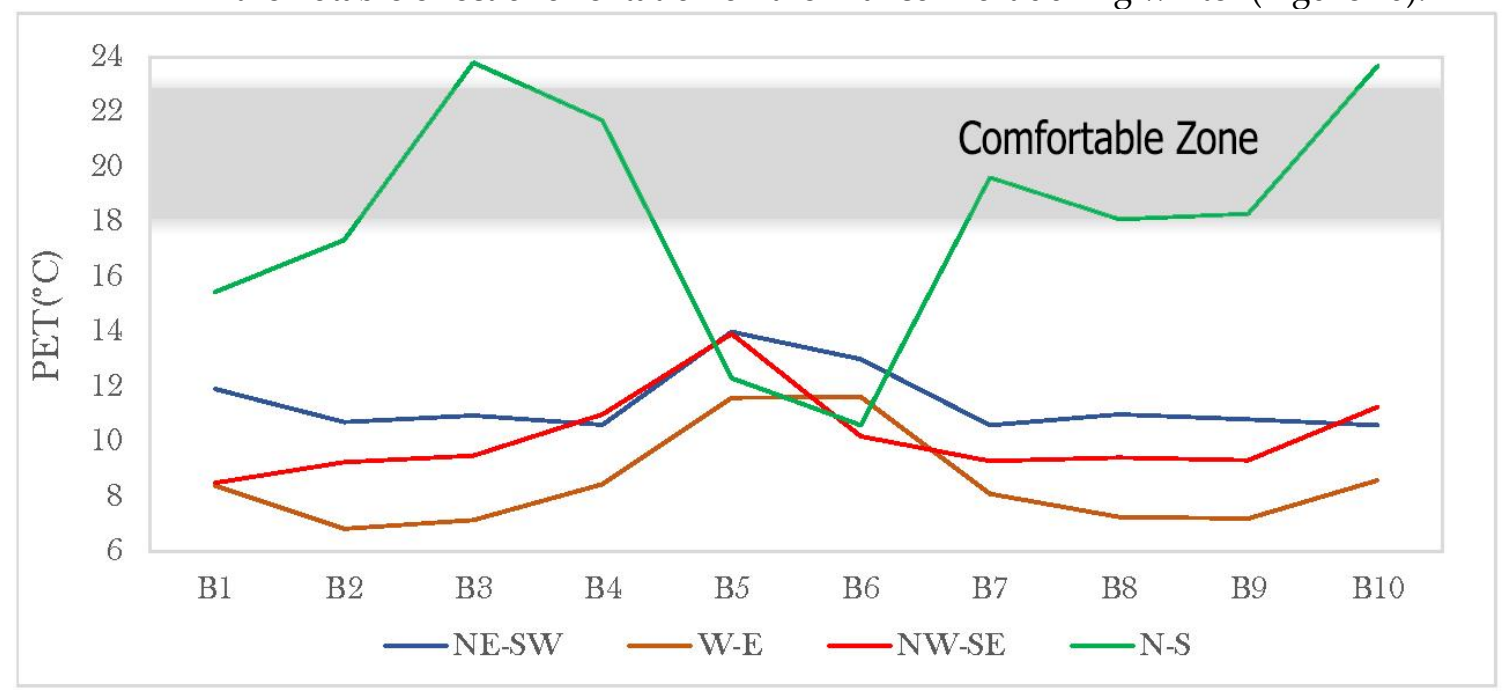


Figure 11. Average PET comparison at Points B1-B10 (in winter)

\subsubsection{The Effect of Changing SVF due to Variations in Street Width on Thermal Comfort (in Winter):}

If the width of a street changes, so does its SVF and the amount of solar radiation it receives. The larger width of the street at points B5 and B6 increased its SVF (Figure 12 and Table 8). At these two points, radiant temperature increased in all orientations. The amount of this rise, however, varies across the orientations and the number of hours of exposure to radiation.

The microclimatic parameters of points B2 and B5, at which width variations caused SVF changes, are listed in Table 9. As shown in Table 8, SVF in B5 (which is in the central opening) is higher than that of B2 (which is located between the blocks). The higher SVF of B5 led to a higher Tmrt $\left(9-13^{\circ} \mathrm{C}\right)$, wind speed $(0.5$ to $1.5 \mathrm{~m} / \mathrm{s})$, and PET in all orientations except for N-S. As the blocks are perpendicular to the prevailing wind in the N-S orientation, the wind had a lower speed between the blocks but its high speed in the opening of the street led to a decrease in PET.

It can be concluded that breaks and street openings between the blocks in all orientations caused a slight amount of thermal comfort in winter, except in the case where this street opening was perpendicular to the prevailing wind. SVF has a strong effect on radiant temperature and wind speed but does affect air temperature and humidity.

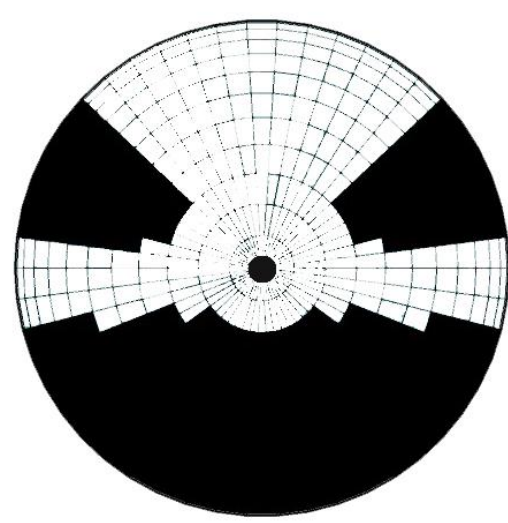

Figure 12. Sky view analysis at B1-B10 (Produced with Sketchup SVF plug-in)

Table 8. Sky view factor values (B1-B10)

\begin{tabular}{ccccccccccc}
\hline Points & B1 & B2 & B3 & B4 & B5 & B6 & B7 & B8 & B9 & B10 \\
\hline SVF Value & 0.58 & 0.47 & 0.46 & 0.5 & 0.64 & 0.62 & 0.47 & 0.45 & 0.46 & 0.57 \\
\hline
\end{tabular}

Table 9. Average MicroClimatic Quantities Comparison at two points B2 and B5 with different SVF (in Winter)

\begin{tabular}{cccccccc}
\hline $\begin{array}{c}\text { Orienta- } \\
\text { tion }\end{array}$ & Point & SVF & T(c) & $\begin{array}{c}\text { Wind } \\
\text { speed(m/s) }\end{array}$ & $\begin{array}{c}\text { Spe- } \\
\text { cific } \\
\text { humid- } \\
\text { ity }\end{array}$ & Tmrt(c) & PET(c) \\
\hline NE-SW & B2 & 0.47 & 8.7 & 2 & 3.7 & 28.8 & 10.7 \\
\hline
\end{tabular}




\begin{tabular}{cccccccc}
\hline & B5 & 0.64 & 8.6 & 1.5 & 3.7 & 38.1 & 14 \\
\hline \multirow{2}{*}{ N-S } & B2 & 0.47 & 8.1 & 0.3 & 3.7 & 27.1 & 17.4 \\
\cline { 2 - 8 } & B5 & 0.64 & 7.9 & 1.8 & 3.7 & 36.2 & 12.3 \\
\hline \multirow{2}{*}{ NW-SE } & B2 & 0.47 & 8.5 & 1.9 & 3.7 & 26.9 & 9.3 \\
\cline { 2 - 8 } & B5 & 0.64 & 8.3 & 1.3 & 3.7 & 35.7 & 13.9 \\
\hline \multirow{2}{*}{ W-E } & B2 & 0.47 & 8.6 & 2.6 & 3.7 & 19.2 & 6.8 \\
\cline { 2 - 8 } & B5 & 0.64 & 8.6 & 1.9 & 3.7 & 33.1 & 11.6
\end{tabular}

Path C1-C10: All points on this path were in the thermal comfort range throughout the day in the N-S orientation. The second thermally suitable orientation was NE-SW whereas the lowest thermal comfort was recorded for the W-E orientation (Figure 13). Path $C$ was a continuous street where blocks were on both sides without any opening (Figure 5). Therefore, the consistency of wind speed along this path prevented notable PET fluctuations in all orientations. A comparison between the thermal comfort of path $B$ and that of path C (Figure 11 and Figure 13) during winter indicates that continuous paths (without disconnections such as squares) can provide better thermal comfort in cold climates.

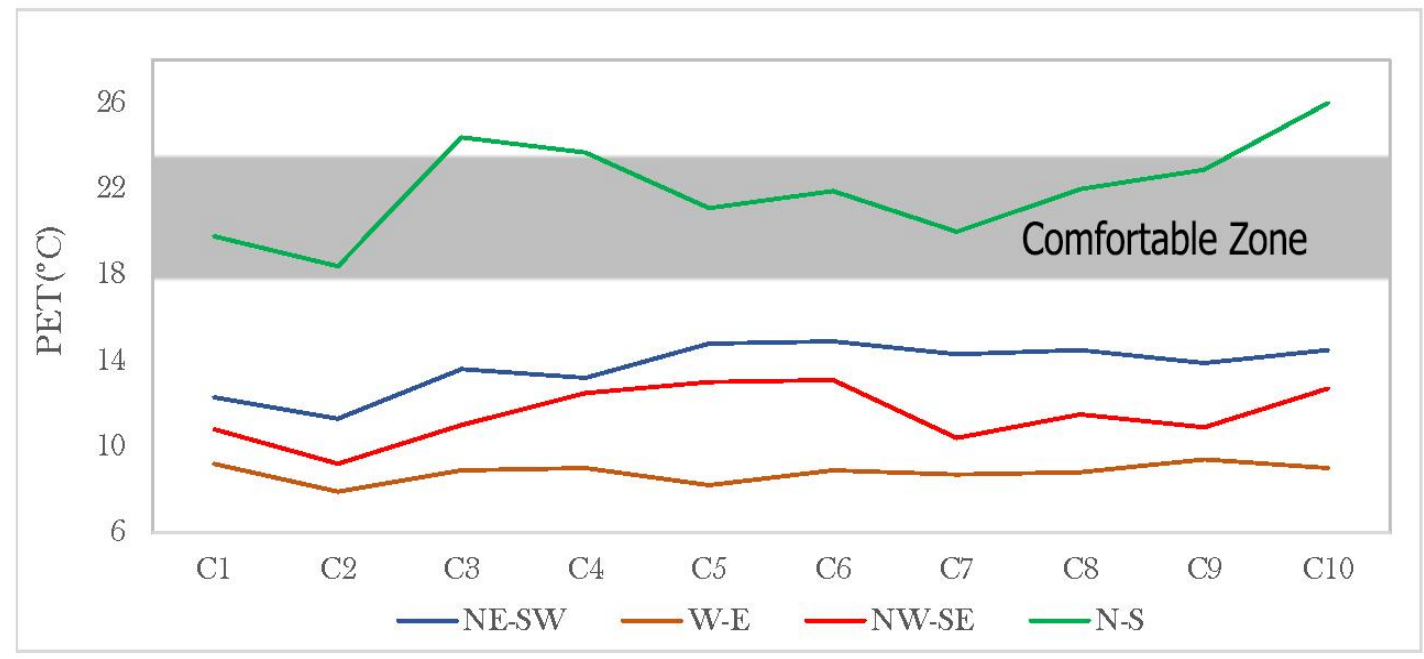

Figure 13. Average PET comparison at Points C1-C10 (in winter) 


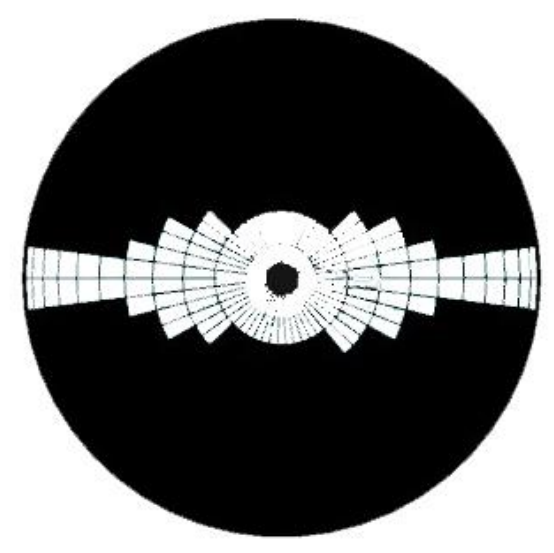

Figure 14. Sky view analysis at C1-C10 (calculated with Sketchup SVF plug-in)

Table 10. Sky view factor values (C1-C10)

\begin{tabular}{ccccccccccc}
\hline Points & C1 & C2 & C3 & C4 & C5 & C6 & C7 & C8 & C9 & C10 \\
\hline $\begin{array}{c}\text { SVF } \\
\text { Value }\end{array}$ & 0.47 & 0.36 & 0.36 & 0.43 & 0.46 & 0.46 & 0.41 & 0.35 & 0.36 & 0.45 \\
\hline
\end{tabular}

\subsubsection{The Effect of Changing SVF due to Variations in Street Width on Thermal Comfort (in} Winter):

Width changes in C increased SVF in the wider part of the path (Figure 14 and Table 10). Points $C 2$ and $C 5$ (wider than C2) have been compared to examine the effect of SVF on microclimatic parameters and thermal comfort. The SVF values of C2 and C5 differ from each other because of the different widths of the street at these two points. Table 11 shows the microclimatic parameters of these two points. At C5, SVF increased, Tmrt increased in all orientations, wind speed decreased (from 0.3 to $0.6 \mathrm{~m} / \mathrm{s}$ ) and PET increased. Therefore, width changes have a strong effect on Tmrt but the resulting thermal comfort is not equal in all orientations. In orientations where more solar radiation was received (N-S and intercardinal orientations), PET rose by a greater amount and created better thermal comfort. In the E-W orientation, the increased width had a trivial impact on PET improvement.

Table11. Average MicroClimatic Quantities Comparison at two points C2 and C5 with different SVF (in Winter)

\begin{tabular}{ccccccccc}
\hline Orientation & Point & SVF & T(c) & $\begin{array}{c}\text { Wind } \\
\text { speed(m/s) }\end{array}$ & $\begin{array}{c}\text { Specific } \\
\text { humidity }\end{array}$ & Tmrt(c) & PET(c) \\
\hline \multirow{2}{*}{ NE-SW } & C2 & 0.36 & 8.7 & 1.8 & 3.7 & 27.4 & 11.3 \\
\cline { 2 - 8 } & C5 & 0.46 & 8.4 & 1.4 & 3.7 & 29 & 14.9 \\
\hline N-S & C2 & 0.36 & 8.4 & 0.4 & 3.7 & 28.3 & 18.5 \\
\hline
\end{tabular}




\begin{tabular}{cccccccc}
\hline & C5 & 0.46 & 8.4 & 0.4 & 3.7 & 32.3 & 21.1 \\
\hline \multirow{2}{*}{ NW-SE } & C2 & 0.36 & 8.4 & 1.8 & 3.7 & 25.4 & 9.3 \\
\cline { 2 - 8 } & C5 & 0.46 & 8.3 & 1.5 & 3.7 & 29.3 & 13 \\
\hline \multirow{2}{*}{ W-E } & C2 & 0.36 & 8.6 & 2.4 & 3.7 & 19 & 7.9 \\
\cline { 2 - 8 } & C5 & 0.46 & 8.5 & 1.8 & 3.7 & 20.5 & 8.2
\end{tabular}

3.2. The Simulation Results in Four Different Orientations in Summer (August 6, 2019/ without Vegetation):

3.2.1. The microclimatic conditions of Point A in a summer day (August 6, 2019)

Air temperature(Ta): There are only slight differences in air temperature values in the four simulated orientations from 06:00 to 18:00. The highest recorded temperature namely $35{ }^{\circ} \mathrm{C}$ belongs to the current orientation (NE-SW) at 12:00. Air temperature in the $\mathrm{W}$-E orientation was very close to the current conditions. The lowest recorded temperature with a decrease of $1{ }^{\circ} \mathrm{C}$ belongs to the N-S orientation (Figure 15).

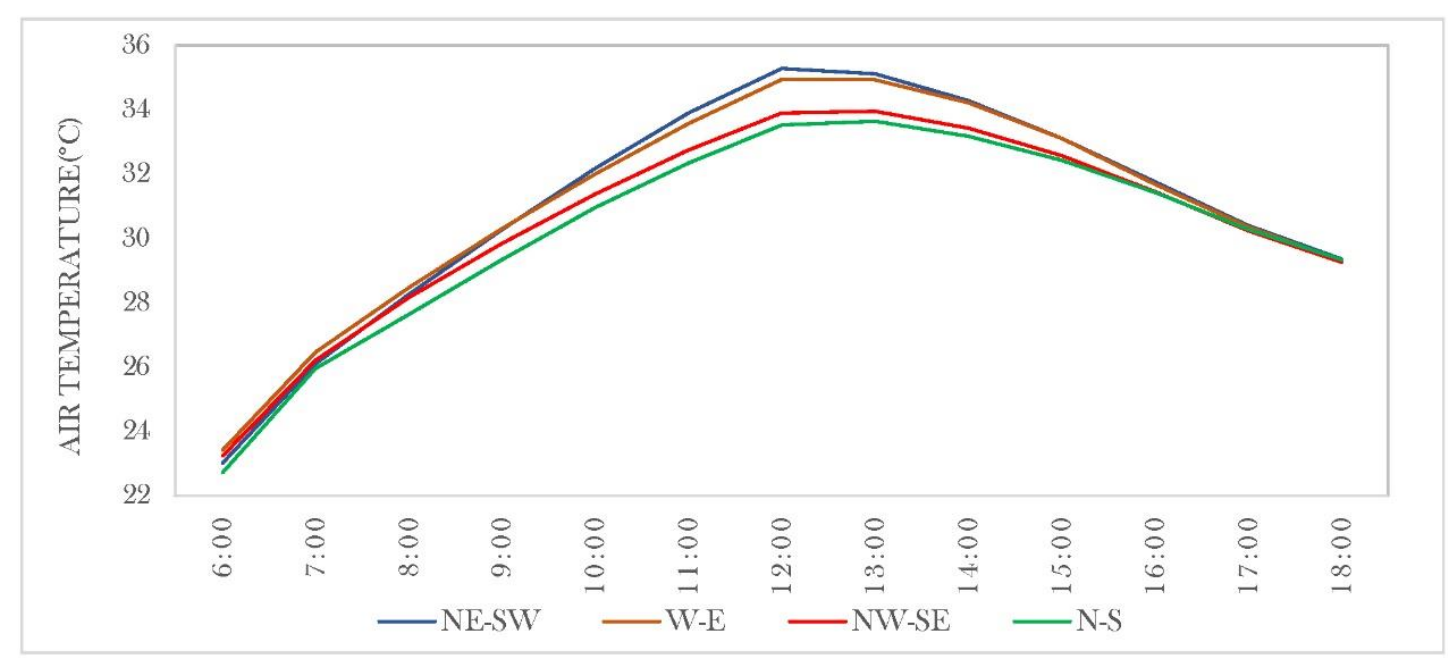

Figure 15: Air temperature $\left(\mathrm{T}_{\mathrm{a}}\right)$ comparison at Point A (in summer)

Wind speed: The values of wind speed at Point $A$ in the different orientations in summer (Figure 16) are equal to the values in winter (Figure 8). In the N-S orientation where the axis of the blocks was perpendicular to the wind direction and the buildings prevented the wind from entering the streets, the speed was lowest. The maximum wind speed (1.8 $\mathrm{m} / \mathrm{s}$ ) belongs to the W-E orientation where the streets were parallel to wind direction (Figure 16). The wind speed in intercardinal orientations fell between these two values (1.3$1.5 \mathrm{~m} / \mathrm{s}) .$. 


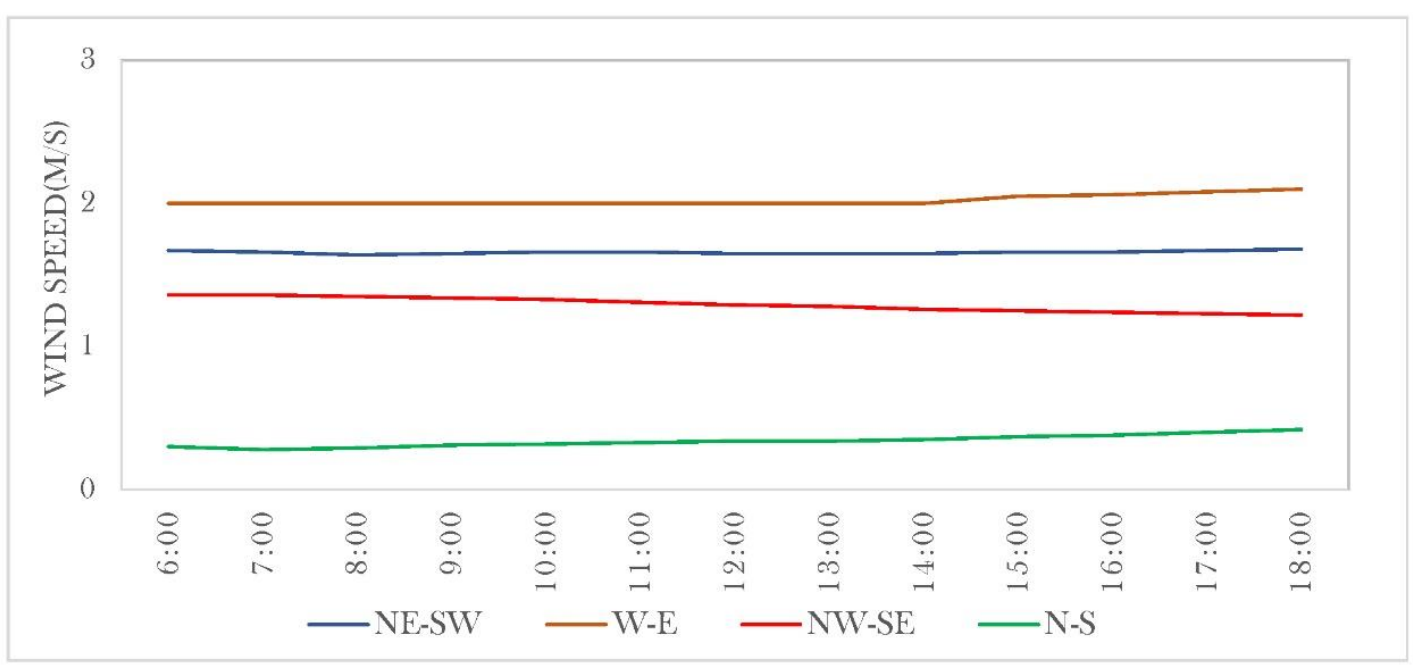

Figure 16: Comparison of wind speed at Point A (in summer)

Mean radiant temperature (Tmrt): Unlike winter during which a higher Tmrt is required for thermal comfort, lower temperatures are desirable during summer. Given the angle of solar radiation and the number of exposure hours, the radiant temperature of Point $\mathrm{A}$ increased in most hours of the day. But it began to decrease in all four orientations from 16:00 onwards (Figure 17). In the NE-SW and N-S orientations, radiant temperature was lower than that of the other two orientations at 06:00 and 07:00. The highest Tmrt belongs to the $\mathrm{W}$-E orientation where the streets received full radiation without any shading.

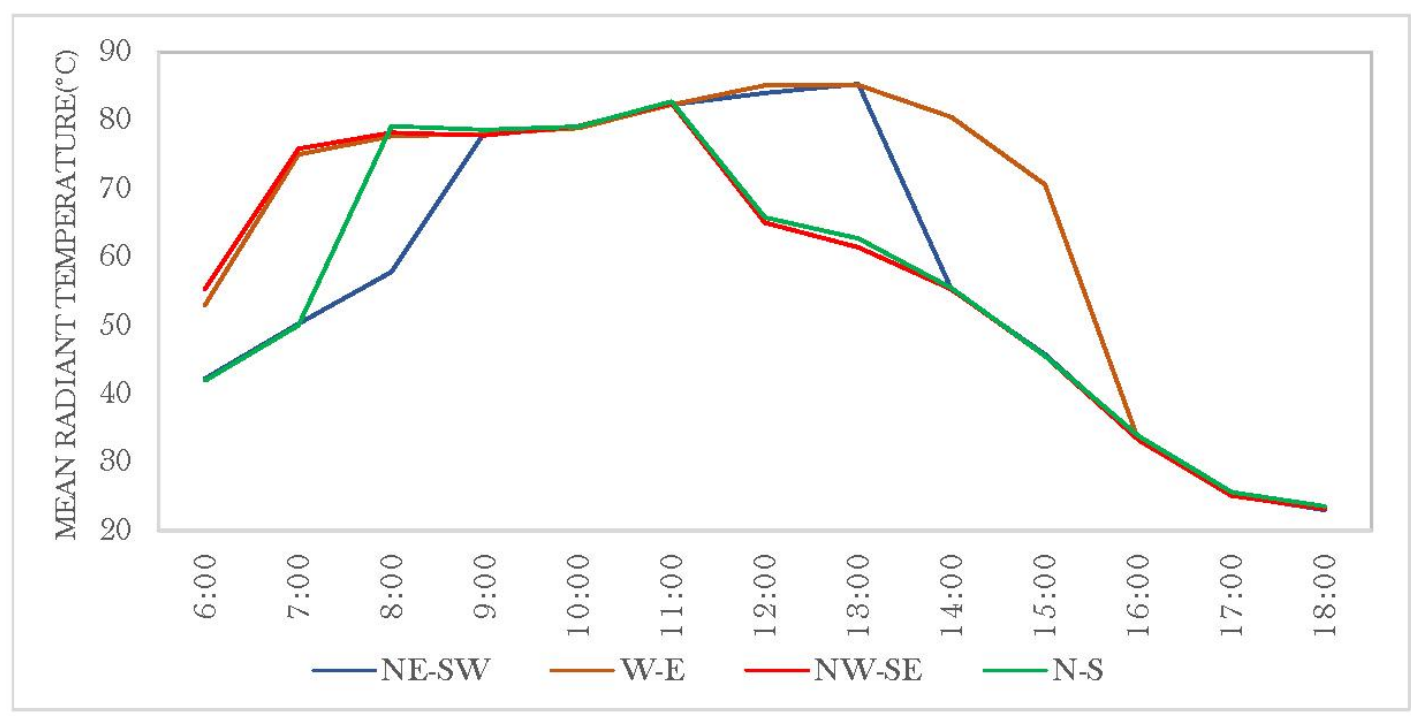

Figure 17: Mean radiant temperature comparison at Point A (in summer)

The different values of Tmrt at Point $\mathrm{A}$ in the E-W orientation during winter and summer (Figure 9 and Figure 17) show that this orientation received the least amount of radiation in winter and the most amount of radiation during summer. The main reason is the oblique angle of sunlight during winter and vertical angle during summer. Therefore, $\mathrm{E}-\mathrm{W}$ is not a suitable orientation for either the cold or the hot climate.

PET: Figure 18 shows that the current orientation (NE-SW) had the lowest PET at Point A in early morning hours (06:00-09:00). In most hours of the day, Point A experienced a "hot" temperature. The maximum recorded temperature, namely $53.4^{\circ} \mathrm{C}$, belongs to the N-S orientation at 11:00. From 16:00 onwards, the temperature fell in all orientations and approached the thermal comfort range. 


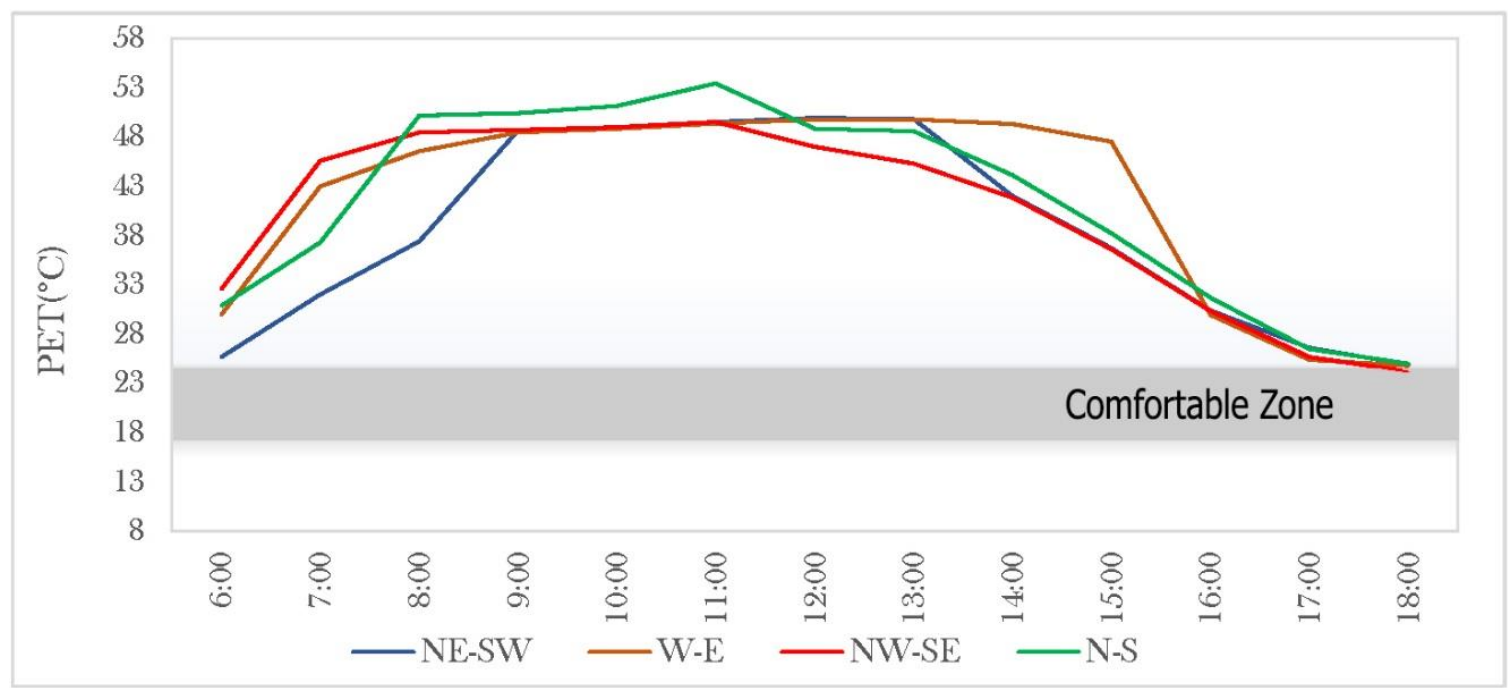

Figure 18: PET comparison at Point A (in summer)

Table 12 summarizes the mean values of the microclimatic parameters for different orientations at point A. A comparison of these values shows that a change in the orientation of the street has a very strong effect on wind speed and radiant temperature. The mean value of PET is lowest in the NE-SW orientation and closer to thermal comfort limit than in other orientations. As can be seen in Figure 18, the PET diagrams of the paths with different orientations are very similar. The mean values at Table 12 show that the orientation of a path has a negligible impact on thermal comfort during summer. Therefore, other design factors need to be taken into account for improving the microclimate of a path during this season.

Table12. Average Microclimate Quantities Comparison at Point A (in Summer)

\begin{tabular}{ccccccc}
\hline Orientation & T(c) & $\begin{array}{c}\text { Wind } \\
\text { speed(m/s) }\end{array}$ & $\begin{array}{c}\text { Spe- } \\
\text { cific } \\
\text { hu- } \\
\text { midity }\end{array}$ & Tmrt(c) & PET(c) & $\begin{array}{c}\text { Com- } \\
\text { fortable } \\
\text { Hours }\end{array}$ \\
\hline NE-SW & 32 & 1.6 & 5.8 & 65.3 & 38.7 & 0 \\
\hline N-S & 30.8 & 0.4 & 5.8 & 56.9 & 41.3 & 0 \\
\hline NW-SE & 31 & 1.3 & 5.8 & 58.5 & 40.4 & 0 \\
\hline W-E & 31.6 & 2 & 5.8 & 66.2 & 41.7 & 0
\end{tabular}

\subsubsection{The microclimatic conditions of paths $B$ and $C$ in a summer day (August 6, 2019)}

The microclimatic parameters of paths $B$ and $C$ were examined for investigation of the impact of SVF on thermal comfort in summer and in different orientations. Path B1B10: The mean value of PET recorded between 06:00 and 18:00 at Points B1-B10 indicates that the NW-SE orientation had the lowest PET but did not fall within the range of thermal comfort (Figure 19). Due to its position in relation to the angle of solar radiation, the N-S orientation had the highest PET but shows a temperature decrease at B5 and B6 in winter (Figure 10). In general, points B1-B10 were far from the desirable thermal comfort range $\left(18-23^{\circ} \mathrm{C}\right)$ in all four orientations on the hot summer day. This shows that a change in the orientation of a path does not improve thermal comfort to a notable degree during summer. Therefore, water bodies, vegetation or seasonal canopies should be used for reducing the amount of radiant energy absorption. 


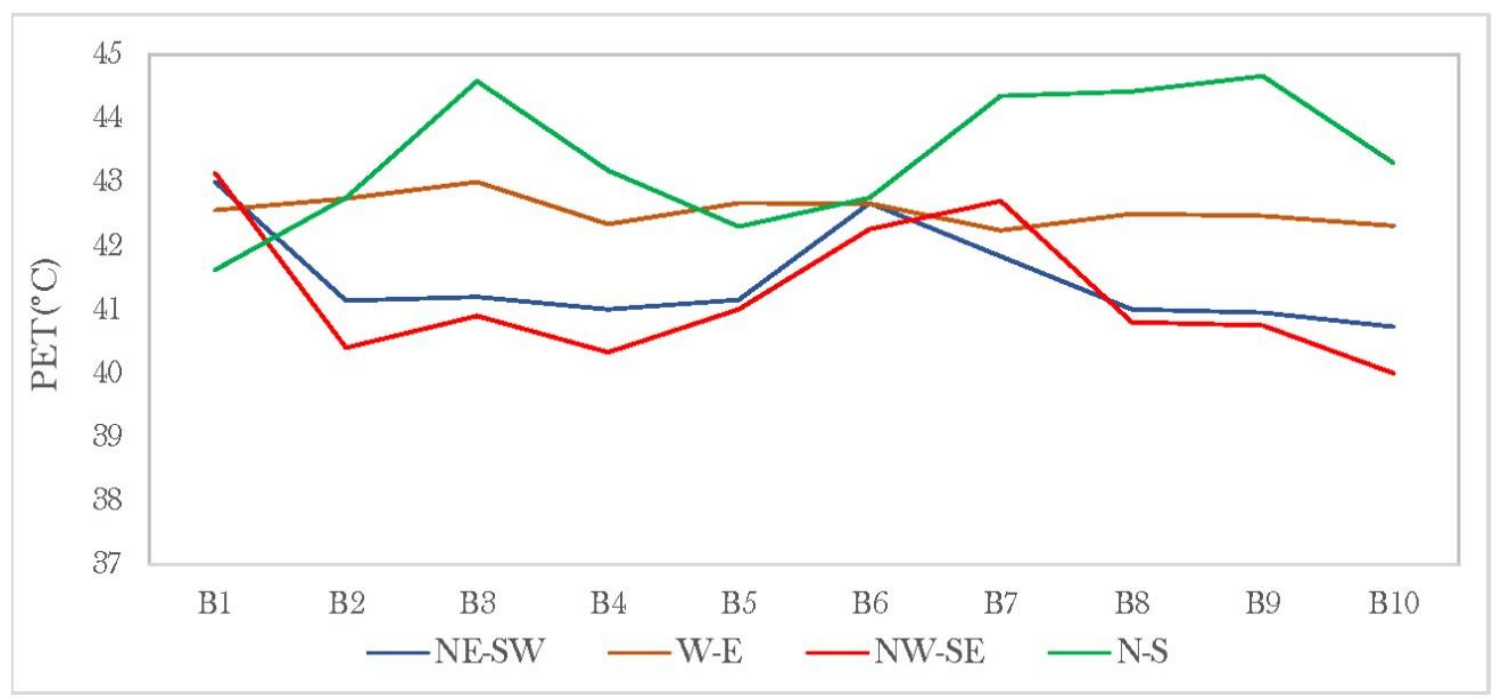

Figure 19. Average (PET) comparison at Points B1-B10 (in summer)

The Effect of SVF changes resulting from Street Width Variations on Thermal Comfort in Path B (in Summer): At points B5 and B6 where the linear block was discontinuous and had an opening, SVF was higher than at points which were between the blocks (Figure 12 and Table 8). To examine the effect of SVF on the microclimatic parameters and thermal comfort, points B3 and B6 (in which SVF was different because of a change in the street width) are compared in Table 13. The change in the width of the street at B6 affected wind speed and the change in the SVF affected radiant temperature. The highest radiant temperature was observed in the N-S orientation in which the maximum wind speed can also be observed at point B6. In the other orientations except for E-W, changes in radiant temperature were remarkable, with B6 experiencing increased temperature. Finally, as Table 13 shows, the small square midway through the street (B1-B10) increased PET by 0$2{ }^{\circ} \mathrm{C}$.

Table 13. Average MicroClimatic Quantities Comparison at two points B2 and B5 with different SVF (in Summer)

\begin{tabular}{cccccccc}
\hline Orientation & Point & SVF & T(c) & $\begin{array}{c}\text { Wind } \\
\text { speed(m/s) }\end{array}$ & $\begin{array}{c}\text { Specific } \\
\text { humidity }\end{array}$ & Tmrt(c) & PET(c) \\
\hline \multirow{3}{*}{ NE-SW } & B2 & 0.47 & 31.9 & 1.9 & 5.8 & 68.9 & 41.1 \\
\cline { 2 - 8 } & B5 & 0.64 & 31.7 & 1.4 & 5.8 & 68.2 & 41.1 \\
\hline \multirow{3}{*}{ N-S } & B2 & 0.47 & 30.8 & 0.4 & 5.8 & 57.5 & 42.8 \\
\hline & B5 & 0.64 & 30.7 & 1.8 & 5.8 & 65.5 & 42.3 \\
\hline \multirow{3}{*}{ NW-SE } & B2 & 0.47 & 31.5 & 1.9 & 5.8 & 59.4 & 40.4 \\
\hline & B5 & 0.64 & 31.2 & 1.3 & 5.8 & 60.8 & 41 \\
\hline \multirow{3}{*}{ W-E } & B2 & 0.47 & 31.8 & 2.7 & 5.8 & 66.7 & 42.7 \\
\hline & B5 & 0.64 & 31.7 & 1.9 & 5.8 & 65.3 & 42.7
\end{tabular}

Path C1-C10: According to the PET graph of this path, the NW-SE orientation has the lowest PET (Fig. 20).

The highest temperature was recorded in the N-S orientation, which made it the most undesirable orientation for thermal comfort during summer. Intercardinal orientations (NE-SW and NW-SE) were more thermally describable. 


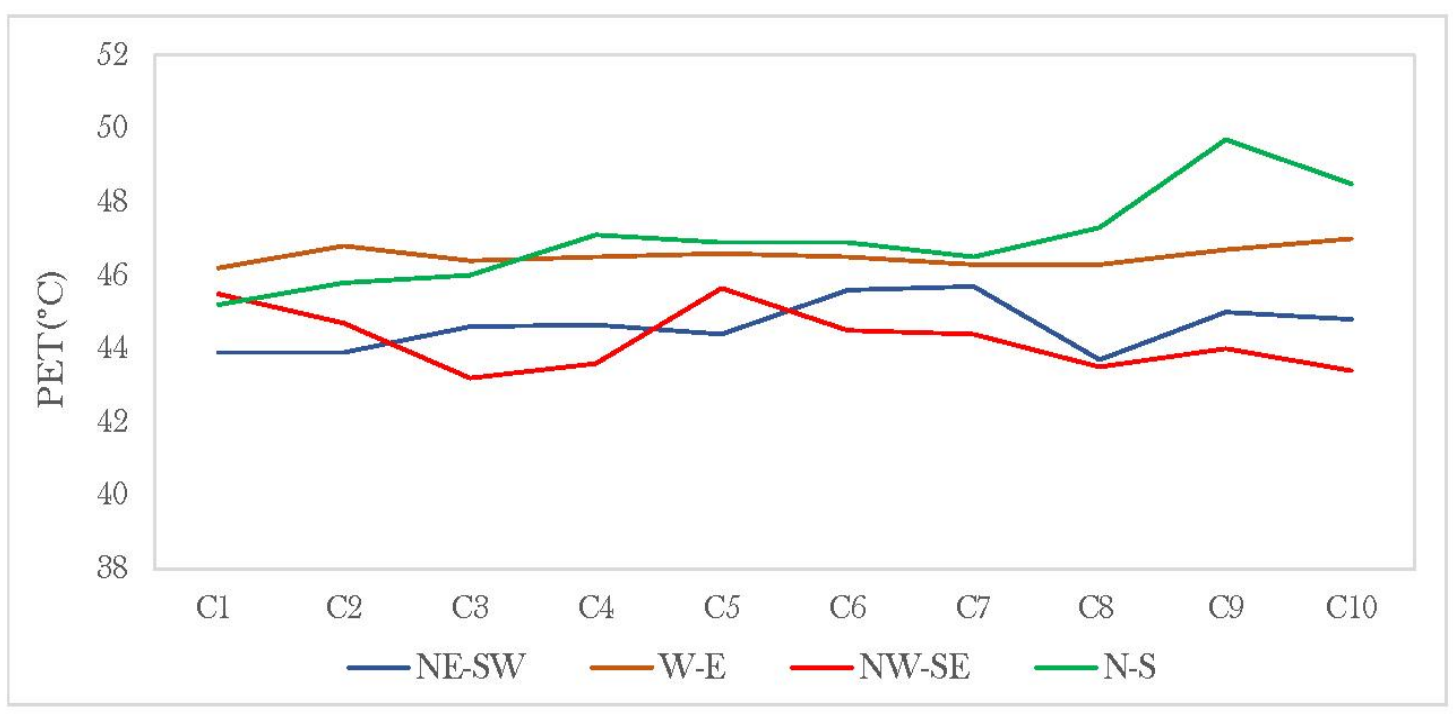

Figure 20. Average PET comparison at Points C1-C10 (in summer)

When a street's orientation is altered, PET changes during winter become more remarkable than those in summer. In path C, PET ranged from 7 to $26^{\circ} \mathrm{C}$ in the four orientations in winter (Figure 13) but ranged from 42 to 47 in summer (Figure 20). This shows that choosing an appropriate orientation for improving thermal comfort is more important in winter than in summer.

The Effect of SVF Changes Resulting from Street Width Variations on Thermal Comfort on Path C (in Summer): The change in the width of path C increased SVF on the wider segment of the street. To examine the effect of SVF on the microclimatic parameters and thermal comfort, points C2 and C5 (which was wider) have been compared in Table 14 . At C5 where SVF increased, wind speed increased $(0.1-0.6 \mathrm{~m} / \mathrm{s})$ as well and radiant temperature changed $\left(0.2-0.4^{\circ} \mathrm{C}\right)$ in different orientations. But the changes in the street width had no significant effect on PET. Although thermal comfort is expected to improve in narrower streets where SVF is lower during summer, only a slight increase in PET was observed compared to the wider segment of the street. Overall, street width had no significant effect on thermal comfort as each 8 -meter increase in the width resulted in only $1^{\circ} \mathrm{C}$ change in the temperature (Table 14).

Table14. Comparison of mean microclimatic values at C2 and C5 with different SVFs (in Summer)

\begin{tabular}{cccccccc}
\hline $\begin{array}{c}\text { Orienta- } \\
\text { tion }\end{array}$ & Point & SVF & T(c) & $\begin{array}{c}\text { Wind } \\
\text { speed(m/s) }\end{array}$ & $\begin{array}{c}\text { Specific } \\
\text { humid- } \\
\text { ity }\end{array}$ & Tmrt(c) & PET(c) \\
\hline \multirow{2}{*}{ NE-SW } & C2 & 0.36 & 31.9 & 1.8 & 5.8 & 67.1 & 44.7 \\
\cline { 2 - 8 } & C5 & 0.46 & 31.5 & 1.4 & 5.8 & 71.7 & 45.6 \\
\hline \multirow{2}{*}{ N-S } & C2 & 0.36 & 31.1 & 0.5 & 5.8 & 58.3 & 45.8 \\
\cline { 2 - 8 } & C5 & 0.46 & 31.2 & 0.4 & 5.8 & 61.8 & 46.9 \\
\hline \multirow{2}{*}{ NW-SE } & C2 & 0.36 & 31.4 & 1.9 & 5.8 & 59.9 & 43.8 \\
\cline { 2 - 8 } & C5 & 0.46 & 31.3 & 1.7 & 5.8 & 61.5 & 44.4 \\
\hline \multirow{2}{*}{ W-E } & C2 & 0.36 & 31.7 & 2.5 & 5.8 & 67.2 & 46.8 \\
\cline { 2 - 8 } & C5 & 0.46 & 31.6 & 1.9 & 5.8 & 65.7 & 46.6
\end{tabular}




\section{4- Discussion}

The streets located in the N-S orientation provided better thermal comfort compared to the streets on the E-W axis. Several studies have shown that N-S street canyons provide the highest level of OTC for pedestrians while the E-W orientation is the worst possible orientation ( [50] [25] [26] [14]). While N-S street canyons provide the highest degree of thermal comfort, buildings constructed along these streets need to consume large amounts of energy for cooling purposes [26] [51]. W-E streets are exposed to direct sunlight and have the highest Tmrt [25]. The NE-SW orientation is the second-best option in urban design and can provide thermal comfort in open spaces to a great degree. The NWSE orientation causes cold stress especially in evenings during winter but can provide thermal comfort during the middle hours of the day; as such, it holds the third rank. The E-W orientation is the worst case. However, certain strategies such as reducing the height of buildings can help improve thermal comfort in this orientation. Regarding open space thermal comfort, middle orientations provide better comfort during summer. Several studies have mentioned the NE-SW orientation as the best design choice for street canyons [52] [53]. Overall, the impact of street width on thermal comfort is not substantial.

Wind speed and Tmrt are the most influential factors that affect thermal comfort in open spaces. Reduction of the time of exposure to sunlight and consequently the change in Tmrt as well as an increase in wind speed causes discomfort in the users of open spaces. Nevertheless, a small degree of coldness was registered in this study in all four orientations before 08:00 and after 18:00.

\section{5- Conclusion}

This paper sought to examine the role of the orientation of the streets of residential blocks on thermal comfort in the cold and mountainous climate. To this end, thermal and climatic comfort conditions were analyzed using a parametric approach for selection of the best orientation for these streets. Parameters such as air temperature, wind speed, Tmrt, PET and SVF were discussed in this regard. The results of this study can help provide an OTC-based guideline for improvement and development of urban environmental qualities. The findings show that optimized design parameters can bring about higher levels of thermal comfort. Based on these findings, Tmrt and wind speed may have the strongest effect on PET. The best street orientation for achieving thermal comfort in this latitude during winter is N-E. In summer, a suitable thermal comfort can be achieved in intercardinal orientations (NW-SE and NE-SW). Since the focus of this study was the cold and mountainous climate, the most important criterion for a climate-responsive orientation is provision of thermal comfort during winter.

It was found out that PET changes are more remarkable in winter than in summer when the orientation of a street changes. In path C, PET ranged from 7 to $26^{\circ} \mathrm{C}$ in all four orientations in winter (Figure 13) but varied from 42 to $47^{\circ} \mathrm{C}$ in summer (Figure 20). This shows that choosing a suitable orientation for improving thermal comfort is more important in winter than in summer.

Although an increase in SVF resulting from an increase in street width can improve thermal comfort during winter, PET rises as well in orientations with more solar radiation. In other words, increased street width does not improve thermal comfort equally in all orientations during winter. For example, in the E-W orientation which receives less solar radiation, adding to a street's width would not change PET. Although thermal comfort in summer is expected to improve in narrower streets where SVF is lower, only a slight increase in PET was observed in this research compared to the wider segment of the street under study. Overall, street width was found out to have no significant effect on thermal comfort (each 8 meters increase in a street's width resulted in only $1^{\circ} \mathrm{C}$ change in temperature). Disjunctions of linear blocks and small squares along a street can decrease PET and improve thermal comfort during summer. Conversely, a lower PET negatively affects thermal comfort during winter. 
Finding the impact of other parameters on OTC merits further research. In addition, determining whether or not N-S is the most suitable orientation for streets in this particular climate requires further study since building height and enclosure can adjust the amount of received radiation and wind speed. A finding of this study suggests that winds which blows vertically onto non-enclosed N-S streets negatively affect thermal comfort during winter and but have a desirable effect during summer. Future studies can address the design parameters that can improve this issue

Author Contributions: Conceptualization, N.D; Data curation, H.S; Formal analysis, F.A; Funding acquisition, H.S; Investigation, N.D; Methodology, N.D and S.H; Project administration, H.S; Resources, H.S; Software, F.A; Supervision, H.S; Validation, N.D and S.H; Visualization, F.A; Writing - original draft, N.D and H.S; Writing - review \& editing, F.A.

Informed Consent Statement: Informed consent was obtained from all subjects involved in the study.

Conflicts of Interest: The authors declare no conflict of interest

\section{References}

1. Moonen P,DefraeyeT,DorerV,BlockenB,CarmelietJ., "Urban physics:effect of the micro-climate on comfort, health and energy demand," Frontiers of Architectural Research, pp. 197-228, 2012.

2. Taleb D, Abu-Hijleh B, "Urban heat islands: Potential effect of organic and structured urban configurations on temperature variations in Dubai," Renewable energy, pp. 747-762, 2012.

3. Aram, F.; Solgi, E.; Higueras García, E.; Mosavi, A. Urban heat resilience at the time of global warming: evaluating the impact of the urban parks on outdoor thermal comfort. Environ. Sci. Eur. 2020, 32(1), 117.

4. Johansson, E., Thorsson, S., Emmanuel, R., Kruger, E, "Instruments and methods in outdoor thermal comfort studies - the need for standardization," Urban Climate, no. 10, p. 346-366, 2014.

5. Aram, F.; Solgi, E.; Baghaee, S.; Higueras García, E.; Mosavi, A.; Band, SS. How parks provide thermal comfort perception in the metropolitan cores; a case study in Madrid Mediterranean climatic zone. Clim. Risk. Manag. 2020, 30, 100245.

6. Hosseini, F.; Sajadzadeh, H.; Aram, F.; Mosavi, A. The Impact of Local Green Spaces of Historically and Culturally Valuable Residential Areas on Place Attachment. Land 2021, 10, 351. doi: 10.3390/land10040351

7. Aram, F.; Solgi, E.; Higueras García, E.; Mosavi, A.; R. Várkonyi-Kóczy, A. The Cooling Effect of Large-Scale Urban Parks on Surrounding Area Thermal Comfort. Energies 2019, 12, 3904. doi: 10.3390/en12203904

8. Chahardowli, M.; Sajadzadeh, H.; Aram, F.; Mosavi, A. Survey of Sustainable Regeneration of Historic and Cultural Cores of Cities. Energies 2020, 13, 2708.

9. Aram, F.; Solgi, E.; Holden, G. The role of green spaces in increasing social interactions in neighborhoods with periodic markets. Habitat Int. 2019, 84, 24-32.H. Bahreini, Urban Design Process, 8th edition,, Tehran: University of Tehran press, 2011.

10. Fathi, S.; Sajadzadeh, H.; Mohammadi Sheshkal, F.; Aram, F.; Pinter, G.; Felde, I.; Mosavi, A. The Role of Urban Morphology Design on Enhancing Physical Activity and Public Health. Int. J. Environ. Res. Public Health 2020, $17,2359$.

11. Taleghani, Mohammad; Kleerekoper, Laura; Tenpierik, van den \& Dobbelsteen Andy, "Outdoor thermal comfort within five different urban forms in the Netherlands," Building and Environment,, pp. 1-14, 2014.

12. Faroughi, M.; Karimimoshaver, M.; Aram, F.; Solgi, E.; Mosavi, A.; Nabipour, N.; Chau, K.-W. Computational modeling of land surface temperature using remote sensing data to investigate the spatial arrangement of buildings and energy consumption relationship. Eng. Appl. Comput. Fluid Mech. 2020, 14, 254-270.

13. Aram, F.; Higueras García, E.; Solgi, E.; Mansournia, S. Urban green space cooling effect in cities. Heliyon $2019,5$.

14. Forgiarini Rupp, R. Vásquez, N G. Lamberts R, "A review of human thermal comfort in the built environment,," Energy and Buildings, vol. 105, pp. 178-205, 2015.

15. Karimimoshaver, M.; Hajivaliei, H.; Shokri, M.; Khalesro, S.; Aram, F.; Shamshirband, S. A Model for Locating Tall Buildings through a Visual Analysis Approach. Appl. Sci. 2020, 10, 6072.

16. Lin, T.P.; Matzarakis, A.; Hwang, R.L., "Shading effect on long-term outdoor thermal comfort," Building and Environment, vol. 45, pp. 213-221, 2010.

17. VDI, Methods for the human-biometerological assessment of climateand air hygiene for urban and regional planningPart I: Climate, VDIguideline 3787. Part 2, Berlin: Beuthen, 1998. 
18. Tseliou, Areti, Tsiros, Ioannis X., Lykoudis, Spyros \& Nikolopoulou,Marialena, "An evaluation of three biometeorological indices for humanthermal comfort in urban outdoor areas under real climatic conditions," Building and Environment, vol. 45, pp. 1346-1352., 2010.

19. Faizi, Mohsen, Monam, Alireza \& Ghazizadeh, Neda, "Evaluation of theEffect of Meteorological and Geographical Parameters on Thermal Discomfort Intensity with the ENVI-met model," Journal of Climate Research, p. In Press., 2011.

20. Mahdinasab, M. Naserzadeh, M, "Determining tourism time calendar in Gahar Lake based on MEMI model," Journal of Applied Geosciences Research, vol. 13, pp. 91-109, 2013.

21. Nadim, Z. Gandomkar, A. Abbasi, AS, "Comparison of quantitative tourism climate indicators to measure the thermal comfort of the environment," Tourism Room 5, vol. 18, pp. 43-58, 2017.

22. Z. Karimian, "Simulation of the environmental impact of widespread and compact green roofs in Yazd',," Iranian Horticultural Science 47, 2016.

23. Bosselmann, P. Arens, E. Dunker, K. Wright ,R, "Urban Form and Climate: Case Study, Toronto,," Journal of the American Planning Association, vol. 61, pp. 226-239, 1995.

24. Ji-YuDeng, Nyuk Hien Wong, "Impact of urban canyon geometries on outdoor thermal comfort in central business districts," Sustainable Cities and Society, p. 101966, 2020.

25. Kuo-Tsang, HuangYi-JhenLi, "Impact of street canyon typology on building's peak cooling energy demand: A parametric analysis using orthogonal experiment," Energy and Buildings, pp. 448-464, 2017.

26. BhaskarDe, Mahua Mukherjee, "Optimisation of canyon orientation and aspect ratio in warm-humid climate: Case of Rajarhat Newtown, India," Urban Climate, pp. 887-920, 2018.

27. Angeliki Chatzidimitriou ,Kleo Axarli, "Street Canyon Geometry Effects on Microclimate and Comfort; A Case Study in Thessaloniki," Procedia Environmental Sciences, pp. 643-650, 2017.

28. Anisha Noori Kakon, Nobuo Mishima, Shoichi Kojima, "Simulation of the urban thermal comfort in a high density tropical city: Analysis of the proposed urban construction rules for Dhaka, Bangladesh," Building Simulation, pp. 291-305, 2009.

29. vanEschMME,LoomanRHJ,deBruin-HordijkGJ., "The effects of urban and building design parameters on solar access to the urban canyon and the potential for direct passive solar heating strategies," Energy and Buildings, vol. 47, pp. 189-200, 2012.

30. Kruger E.L.; Minella F.O. \& Rasia F., '"'Impact of urban geometry on outdoor thermal comfort and air quality from field measurements in Curitiba, Brazil," Building and Environment, vol. 46, pp. 621-634, 2011.

31. Berkovic S, Yezioro A, Bitan A., "Study of thermal comfort in courtyards in a hot arid climate," Solar Energy, vol. 86, pp. 117386, 2012

32. E.Andreou, "Thermal comfort in outdoor spaces and urban canyon microclimate," Renewable Energy, pp. 182-188, 2013.

33. Watson, I. D. \& Johnson, G. T., "Graphical Estimation of Sky View-Factors in Urban Environments," International Journal of Climatology, vol. 7, pp. 193-197, 1987.

34. FBourbia, H.B Awbi, "Building cluster and shading in urban canyon for hot dry climate: Part 1: Air and surface temperature measurements," Renewable Energy, vol. 29, no. 2, pp. 249-262, 2004.

35. Bourbia F, Boucheriba F, "Impact of street design on urban microclimate for semi arid climate(Constantine)," Renewable Energy, vol. 35, pp. 343-7, 2010.

36. Hwang, R.L.; Lin, T.P.; Matzarakis, "A. Seasonal effects of urban street shading on long-term outdoor thermal," Building and Environment, vol. 46, pp. 863-870, 2011.

37. Maryam Jafari, Mohsen Taban, Mohsen Saffaripoor, "Evaluation of thermal comfort in urban street (Case study: Chamran street, Kermanshah)," Journal of Environmental Science, vol. 45, no. 4, pp. 589-603, 2020.

38. Zheng Tan ,Kevin Ka-LunLau, Edward Ng, "Planning strategies for roadside tree planting and outdoor comfort enhancement in subtropical high-density urban areas," Building and Environment, vol. 120, pp. 93-109, 2017.

39. Jiayi Mi , Bo Hong, Ting Zhang, Boze Huang, Jiaqi Niu, "Outdoor thermal benchmarks and their application to climateresponsive designs of residential open spaces in a cold region of China," Building and Environment, vol. 169, no. 106592, 2020.

40. Jing Du, Cheng Sun,Qiuke Xiao, Xin Chen, Jing Liu, "Field assessment of winter outdoor 3-D radiant environment and its impact on thermal comfort in a severely cold region," Science of The Total Environment, vol. 709, 2020.

41. BhaskarDe, Mahua Mukherjee, "“Optimisation of canyon orientation and aspect ratio in warm-humid climate: Case of Rajarhat Newtown, India"," Urban Climate, vol. 24, pp. 887-920, 2018.

42. Sofia Thorsson, Fredrik Lindberg, Ingegärd Eliasson, Björn Holmer, "Different methods for estimating the mean radiant temperature in an outdoor urban setting," International Journal of Climatology Royal Meteorological Society, vol. 27, pp. 1983-1993, 2007.

43. Matzarakis, A.; Mayer, H.; Iziomon, M, "Applications of a universal thermal index: Physiological equivalent temperature.," International Journal of Biometeorology, vol. 43, pp. 76-84, 1999.

44. S. Lenzholzer, "'"Research and design for thermal comfort in Dutch urban squares,"," Resources, Conservation and Recycling, vol. 64, pp. 39-48, 2012.

45. Nastaran Abdollahzadeh, Nimish Biloria, "Outdoor thermal comfort: Analyzing the impact of urban configurations on thethermal performance of street canyons in the humid subtropical climate of Sydney," Frontiers of Architectural Research, 2020.

46. Katia Perini, Ata Chokhachian, Sen Dong, Thomas Auer, "Modeling and Simulating Urban Outdoor Comfort:Coupling ENVIMet and TRNSYS by Grasshopper," Energy and Buildings, vol. 152, pp. 373-384, 2017.

47. N. E. S. P. o. Iran, "Hamedan," /http://www.iran.ir/about/city/hamedan/, 2013.

48. S. F. E. S. Al-Islami, "Climatic study of Hamedan housing," Soffeh, Art and Architecture Quarterly, vol. 53, pp. 53-86, 2011. 
49. BAHMANI ELMIRA, GODARZI MOHAMMAD MEHDI, ZAREIE MOHAMMAD EBRAHIM, "ANALYTICAL APPROACH ON KURD (KURDISH) ARCHITECTURE TOWARDS DESIGNING RESIDENTIAL COMPLEX IN OLD TEXTURE OF SANANDAJ CITY," JOURNAL OF STUDIES ON IRANIAN ISLAMIC CITY, vol. 7, no. 26, pp. 55-69, 2017.

50. E. Andreou, "Thermal comfort in outdoor spaces and urban canyon microclimate," Renewable Energy, vol. 55, pp. 182-188, 2013.

51. Mohammed A.Bakarman , Jae D.Chang, "The Influence of Height/width Ratio on Urban Heat Island in Hot-arid Climates," Procedia Engineering, vol. 118, pp. 101-108, 2015.

52. S. Sudprasert, "Evaluation of energy savings by retrofitting of the building envelope of air-conditioned row house," Journal of Architectural/Planning Research and Studies (JARS), vol. 1, no. 16, pp. 83-92, 2019.

53. D. Mukherjee, "A Review Study on the Thermo Physical Properties and Storage Applications of Phase Change Materials," World Scientific News, vol. 98, pp. 185-198, 2018.

54. Angeliki Chatzidimitriou, Kleo Axarli, "Street Canyon Geometry Effects on Microclimate and Comfort; A Case Study in Thessaloniki," Procedia Environmental Sciences, vol. 38, pp. 643-650, 2017.

55. Knez, I., Thorsson, S, "Influences of culture and environmental attitude on thermal,emotional and perceptual evaluations of a public square," Int. J. Biometeorol, no. 50, p. 258-268, 2006. 